\title{
Summary of CPAS EDU Testing Analysis Results
}

\author{
Leah M. Romero ${ }^{1}$ \\ Aerodyne, LLC, Houston, TX, 77058 \\ and
}

Kristin J. Bledsoe ${ }^{1}$, John Davidson ${ }^{2}$, Megan E. Engert ${ }^{2}$, Usbaldo Fraire Jr. ${ }^{2}$, Fernando S. Galaviz ${ }^{2}$, Patrick J. Galvin ${ }^{2}$, Eric S. Ray ${ }^{1}$, Jose Varela ${ }^{3}$

The Orion program's Capsule Parachute Assembly System (CPAS) project is currently conducting its third generation of testing, the Engineering Development Unit (EDU) series. This series utilizes two test articles, a dart-shaped Parachute Compartment Drop Test Vehicle (PCDTV) and capsule-shaped Parachute Test Vehicle (PTV), both of which include a full size, flight-like parachute system and require a pallet delivery system for aircraft extraction. To date, 15 tests have been completed, including six with PCDTVs and nine with PTVs. Two of the PTV tests included the Forward Bay Cover (FBC) provided by Lockheed Martin. Advancements in modeling techniques applicable to parachute fly-out, vehicle rate of descent, torque, and load train, also occurred during the EDU testing series. An upgrade from a composite to an independent parachute simulation allowed parachute modeling at a higher level of fidelity than during previous generations. The complexity of separating the test vehicles from their pallet delivery systems necessitated the use the Automatic Dynamic Analysis of Mechanical Systems (ADAMS) simulator for modeling mated vehicle aircraft extraction and separation. This paper gives an overview of each EDU test and summarizes the development of CPAS analysis tools and techniques during EDU testing.

\section{Nomenclature}

$\begin{array}{ll}\text { CDR } & =\text { Critical Design Review } \\ \text { CDT } & =\text { Cluster Development Tests } \\ \text { CG } & =\text { Center of Gravity } \\ \text { CM } & =\text { Crew Module } \\ \text { CMS } & =\text { Cradle Monorail System } \\ \text { CPAS } & =\text { Capsule Parachute Assembly System } \\ \text { CPSS } & =\text { Cradle and Platform Separation System } \\ \delta_{1} & =\text { Over-inflation angle } \\ \delta_{2} & =\text { Suspension line half convergence angle } \\ \text { DSS } & =\text { Decelerator Systems Simulation } \\ \text { DSSA } & =\text { Decelerator Systems Simulation Application } \\ \text { EDU } & =\text { Engineering Development Unit of CPAS testing } \\ \text { FBCP } & =\text { Forward Bay Cover Parchute } \\ \text { Gen I } & =\text { First Generation of CPAS testing } \\ \text { Gen II } & =\text { Second Generation of CPAS testing } \\ \text { JETS } & =\text { JSC Engineering, Technology, and Sciences (contract) } \\ \text { JSC } & =\text { Johnson Space Center }\end{array}$

\footnotetext{
${ }^{1}$ Analysis Engineer, GN\&C, Aerosciences, and Tech Transfer/EPO, 2224 Bay Area Blvd., Houston, TX. AIAA Member.

${ }^{2}$ Analysis Engineer, GN\&C, Aerosciences, and Tech Transfer/EPO, 2224 Bay Area Blvd., Houston, TX. Nonmember.

${ }^{3}$ Analysis Engineer, GN\&C, Aerosciences, and Tech Transfer/EPO, 2224 Bay Area Blvd., Houston, TX. AIAA Senior Member.
} 


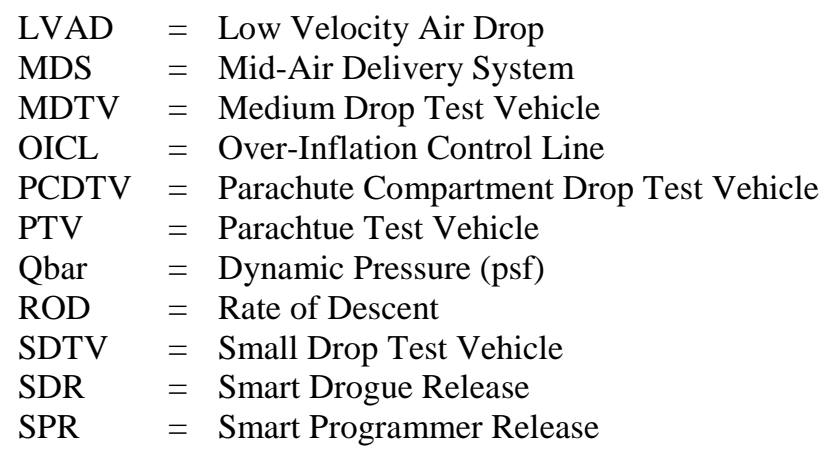

\section{Introduction}

$\mathrm{T}$ HE Orion spacecraft will use a series of parachutes to slow its descent and splash down safely. The parachute system, known as the Capsule Parachute Assembly System (CPAS), is being designed by NASA; Jacobs Engineering's JSC Engineering, Technology, and Sciences (JETS) consortium; and Airborne Systems. The CPAS configuration consists of three mortar-deployed Forward Bay Cover Parachutes (FBCPs), two mortar-deployed Drogue parachutes, three mortar-deployed Pilot parachutes, and three Pilot-deployed Main parachutes.

The first generation (Gen I) of CPAS testing consisted of thirteen tests executed in 2007-2008. Two papers by the Jacobs Analysis team published in 2009 summarize Gen I Drogue, and Main parachute inflation and load performance results. ${ }^{1,2}$ The second generation (Gen II) consisted of nine tests from 2009-2010. Thirteen additional papers by the Jacobs Analysis team were published in 2011 summarizing new avionics hardware ${ }^{3}$, modeling and testing techniques ${ }^{3}$, testing results and lessons learned ${ }^{4}$, and system verification and validation plans ${ }^{5}$. EDU testing began in 2011 and may extend into 2016. The Analysis team published eleven papers in 2013 covering EDU analysis and testing. These papers discuss modeling improvements, ${ }^{6,7,8,9,10}$ and contain test reconstruction updates ${ }^{11,12,13}$ and summaries of the individual vehicle test techniques ${ }^{14,15,16}$. A timeline of all three test series and the associated test vehicles is depicted in Fig. 1.

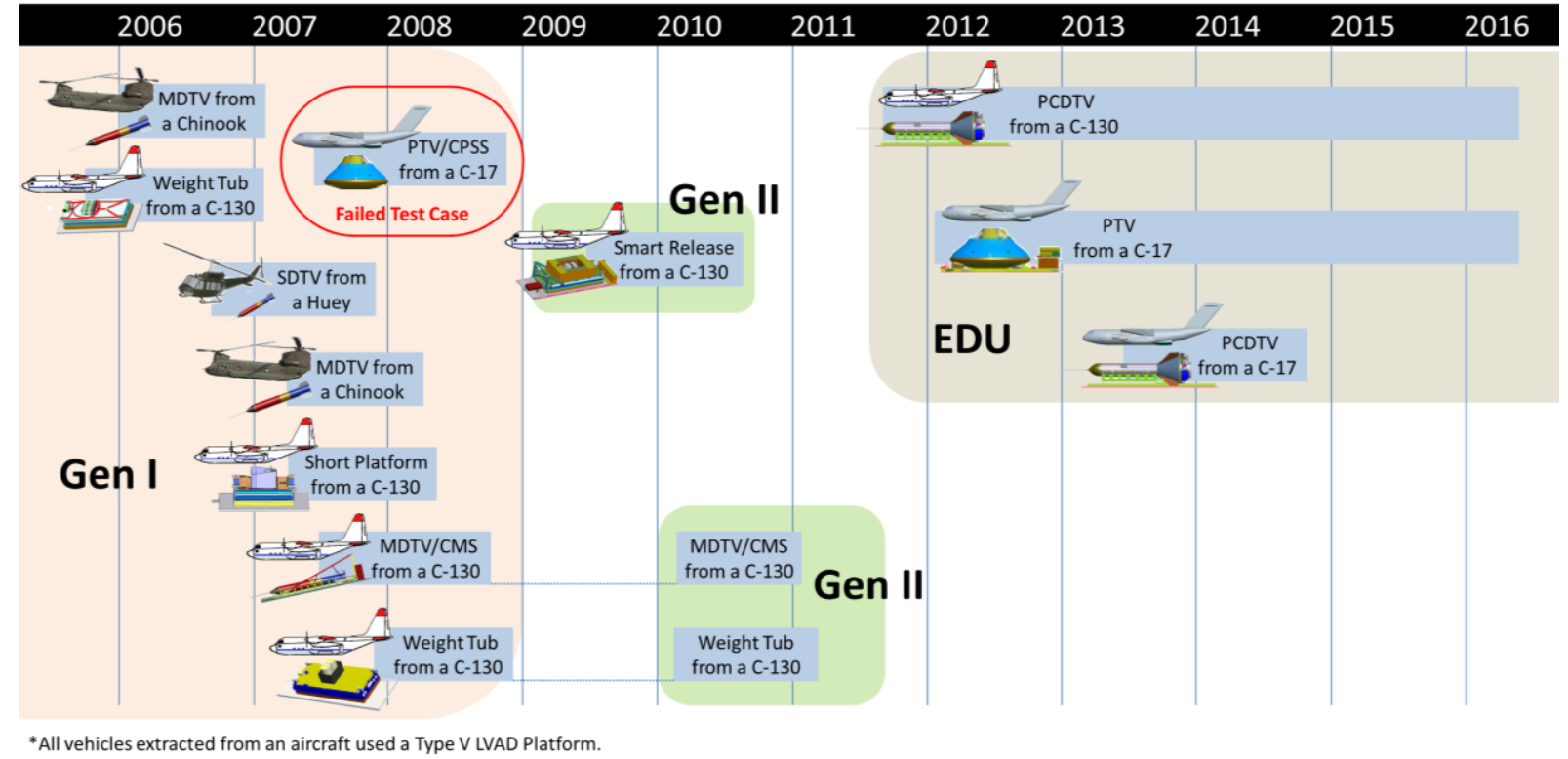

Figure 1. Evolution of CPAS test vehicles and techniques.

\section{Testing Overview}

This section presents a brief summary of each EDU drop test by test techniques. The test vehicles and test techniques are described in detail in Ref. 14 and 15. The initial tests were used to understand the parachute and test support equipment systems. Once confidence was gained in the test techniques and vehicle stability, the test complexity, altitude, and dynamic pressure were gradually increased then varied for failure scenario testing. Following the first EDU test, CDT-3-1, a nominal system test, the test complexity was generally increased with simulated

American Institute of Aeronautics and Astronautics 
parachute failures and trajectory changes to achieve more Orion-like parachute deployment conditions. Architecture diagrams for each test are shown in Appendix A.

An overview of the test objectives is shown in Table 1. The first nine tests had a planned extraction altitude of 25,000 ft-Mean Sea Level (MSL), the upper limit of the Air Force Low Velocity Air Drop (LVAD) envelope. Subsequent tests, except for CDT-3-13 (dropped from 13,000 ft-MSL for an Orion pad abort-like Main parachute deployment), had planned extraction altitude of 35,000 ft-MSL so that the full parachute sequence could be conducted at the nominal Orion entry altitudes. CPAS received Air Force approval to drop from that altitude beginning with CDT-3-11. The higher altitude can pose risks to the hardware if the increased inflation and snatch loads are not properly accounted for. Due to range safety and test support hardware concerns, respectively, both CDT-3-10 and CDT-3-15 were initiated from 25,000 ft-MSL. The concerns are being addressed through hardware modifications and simulation refinements so that testing from 35,000 ft-MSL may occur for the remaining EDU and all qualification tests, pending test objectives.

Table 1. Test Objectives Overview

\begin{tabular}{|c|c|c|c|c|c|c|c|c|}
\hline \multirow{2}{*}{$\begin{array}{c}\text { Test } \\
\text { Number }\end{array}$} & \multirow{2}{*}{$\begin{array}{l}\text { Test } \\
\text { Date }\end{array}$} & \multirow{2}{*}{$\begin{array}{c}\text { Test } \\
\text { Vehicle }\end{array}$} & \multirow{2}{*}{$\begin{array}{c}\text { Targeted } \\
\text { Extraction } \\
\text { Altitude } \\
\text { (MSL) }\end{array}$} & \multicolumn{4}{|c|}{$\begin{array}{c}\text { Test Parachute } \\
\text { Number in Cluster }\end{array}$} & \multirow{2}{*}{ Primary Test Objective(s) } \\
\hline & & & & FВCP & Drg. & PIt. & Main & \\
\hline CDT-3-1 ${ }^{17}$ & $09 / 21 / 11$ & PCDTV & $25 \mathrm{kft}$ & - & 2 & 3 & 3 & Nominal system \\
\hline CDT-3-2 ${ }^{18}$ & $12 / 20 / 11$ & PCDTV & $25 \mathrm{kft}$ & - & 2 & 2 & 2 & Drg skip $2^{\text {nd }}$, Plt $\&$ Main fail \\
\hline CDT-3-3 ${ }^{19}$ & $02 / 29 / 12$ & PTV & $25 \mathrm{kft}$ & - & 2 & 3 & 3 & $\begin{array}{l}\text { Nominal system with flight-like } \\
\text { wake behind PTV }\end{array}$ \\
\hline CDT-3-4 ${ }^{20}$ & $04 / 17 / 12$ & PCDTV & $25 \mathrm{kft}$ & - & 2 & 3 & 3 & High Q Drg deploy, Main skip $2^{\text {nd }}$ \\
\hline CDT-3-5 ${ }^{21}$ & $07 / 18 / 12$ & PTV & $25 \mathrm{kft}$ & - & 2 & 3 & 3 & Main skip $1^{\text {st }}$ \\
\hline CDT-3-6 ${ }^{22}$ & $08 / 28 / 12$ & PCDTV & $25 \mathrm{kft}$ & - & 2 & 3 & 3 & Max Q Drg deploy \\
\hline CDT-3-7 ${ }^{23}$ & $12 / 20 / 12$ & PTV & $25 \mathrm{kft}$ & - & 1 & 3 & 3 & Drg fail \\
\hline CDT-3-8 ${ }^{24}$ & $02 / 12 / 13$ & PCDTV & $25 \mathrm{kft}$ & 3 & 2 & 3 & 3 (1 flagging) & $\begin{array}{l}\text { High Q Drg Deploy, Drg skip }{ }^{\text {st }} \text {, } \\
\text { flagging Main }\end{array}$ \\
\hline CDT-3-9 ${ }^{25}$ & $05 / 01 / 13$ & PTV & $25 \mathrm{kft}$ & - & 1 & 3 & 3 & Drg fail, Main skip $1^{\text {st }}$ \\
\hline CDT-3-11 26 & $07 / 24 / 13$ & PTV & $35 \mathrm{kft}$ & - & 2 & 3 & 3 (1 released) & Main skip $1^{\text {st }} \&$ released \\
\hline CDT-3-10* & $01 / 16 / 14$ & $\begin{array}{l}\text { PTV with } \\
\text { FBC }\end{array}$ & $25 \mathrm{kft}$ & 3 & 2 & 3 & 3 & FBC \& nominal system \\
\hline CDT-3-12 27 & $02 / 26 / 14$ & PCDTV & $35 \mathrm{kft}$ & 3 & 2 & 2 & 2 & Max Q Drg deploy, Plt \& Main fail \\
\hline CDT-3-13* & $04 / 23 / 14$ & PTV & $13 \mathrm{kft}$ & - & - & 3 & 3 & Straight to Mains deploy \\
\hline CDT-3-14* & $06 / 25 / 14$ & $\begin{array}{l}\text { PTV with } \\
\text { FBC }\end{array}$ & $35 \mathrm{kft}$ & 3 & 2 & 3 & 3 & FBC \& Main skip $2^{\text {nd }}$ \\
\hline CDT-3-15* & $12 / 18 / 14$ & PTV & $25 \mathrm{kft}$ & - & 2 & 2 & 2 & $\begin{array}{l}\text { Textile risers, Main design changes } \\
\text { (reduced riser length and OICL) }\end{array}$ \\
\hline
\end{tabular}

*Analysis report not released when this document was written.

A summary of the test results is shown in Table 2. The actual extraction altitude is different than the planned due to day-of-flight atmosphere conditions. For the first test of each vehicle, the dynamic pressure (Qbar) at Drogue deploy was less than 40 psf. Each subsequent Parachute Compartment Drop Test Vehicle (PCDTV) targeted a higher Qbar, while most Parachute Test Vehicle (PTV) tests continued to deploy the Drogues at a low Qbar, below 50 psf. The PTV's bottom cross section, representing the Orion heat shield, results in a large drag area which causes reaching high Qbar values difficult without an extended free fall phase. Though this was done on CDT-3-14, it was carefully balanced against vehicle stability. The individual and cluster loads (if applicable) are recorded in Table 2 along with the stage in which it occurred: $1^{\text {st }}, 2^{\text {nd }}$, or Full Open (FO). The FBCPs were not used until CDT-3-8, where they were implemented as programmer parachutes instead of in their Orion role to separate the FBC. They served the same purpose on CDT-3-12. Although Pilots were used on each test, Pilot load data was not recorded or reconstructed in simulations until CDT-3-6. The final two columns in the table show the Main parachute rate of descent (ROD) and fly-out (mean and peak) values. ${ }^{12,31}$ For more information on the test vehicles and individual tests, see the following subsections.

American Institute of Aeronautics and Astronautics 
Table 2. Test Results Summary

\begin{tabular}{|c|c|c|c|c|c|c|c|c|c|c|}
\hline \multirow{3}{*}{$\begin{array}{c}\text { Test } \\
\text { Number }\end{array}$} & \multirow{3}{*}{$\begin{array}{c}\text { Extraction } \\
\text { Altitude } \\
\text { (ft-MSL) }\end{array}$} & \multirow{3}{*}{$\begin{array}{c}\text { Qbar } \\
\text { @ } \\
\text { Drg. } \\
\text { Deploy } \\
\text { (psf) }\end{array}$} & \multicolumn{6}{|c|}{ Peak Load - Load (Klbf)/Stage } & \multirow{3}{*}{$\begin{array}{l}\text { Main } \\
\text { Mean } \\
\text { ROD } \\
(\mathbf{f t} / \mathbf{s})\end{array}$} & \multirow{3}{*}{$\begin{array}{c}\text { Main Fly- } \\
\text { out Angle - } \\
\text { Mean/Peak } \\
\text { (deg) }\end{array}$} \\
\hline & & & \multirow{2}{*}{ FBCP } & \multicolumn{2}{|c|}{ Drg. } & \multirow{2}{*}{ Plt. } & \multicolumn{2}{|c|}{ Main } & & \\
\hline & & & & Ind. & Clstr. & & Ind. & Clstr. & & \\
\hline CDT-3-1 & 25,267 & 37 & - & 14 / FO & $26 / F O$ & NA & $18 / 1 \mathrm{st}$ & $46 / 1 \mathrm{st}$ & 25 & NA \\
\hline CDT-3-2 & 25,058 & 75 & - & $22 / \mathrm{FO}$ & $40 / \mathrm{FO}$ & NA & $28 / \mathrm{FO}$ & $48 / 1 \mathrm{st}$ & 30 & $12 / 21$ \\
\hline CDT-3-3 & 25,249 & 34 & - & $16 / \mathrm{FO}$ & $28 / \mathrm{FO}$ & NA & $22 / 1 \mathrm{st}$ & $47 / 1 \mathrm{st}$ & 25 & $16 / 26$ \\
\hline CDT-3-4 & 25,103 & 106 & - & $21 / \mathrm{FO}$ & $40 / \mathrm{FO}$ & NA & $32 / \mathrm{FO}$ & $55 / 1 \mathrm{st}$ & 25 & NA \\
\hline CDT-3-5 & 25,079 & 34 & - & $15 / \mathrm{FO}$ & $28 / \mathrm{FO}$ & NA & $31 / \mathrm{FO}$ & $48 / 1 \mathrm{st}$ & 25 & $16 / 27$ \\
\hline CDT-3-6 & 25,048 & 151 & - & $29 / 1 \mathrm{st}$ & $51 / \mathrm{FO}$ & $1.8 \mathrm{Indv}$. & $23 / \mathrm{FO}$ & $62 / \mathrm{FO}$ & 25 & $16 / 25$ \\
\hline CDT-3-7 & 24,990 & 35 & - & \multicolumn{2}{|c|}{$22 / \mathrm{FO}$} & NA & $23 / \mathrm{FO}$ & $49 / 1 \mathrm{st}$ & 25 & $16 / 27$ \\
\hline CDT-3-8 & 25,187 & 120 & 8.8 Clstr. & $31 / 2^{\text {nd }}$ & $43 / 1 \mathrm{st}$ & NA & $29 / 1 \mathrm{st}$ & $58 / 1 \mathrm{st}$ & 31 & $13 / 22$ \\
\hline CDT-3-9 & 24,988 & 49 & - & \multicolumn{2}{|c|}{$22 / \mathrm{FO}$} & 3.1 Indv. & $28 / 2 n d$ & $64 / 1 \mathrm{st}$ & 25 & $16 / 28$ \\
\hline CDT-3-11 & 35,264 & 48 & - & $10 / \mathrm{FO}$ & $28 / \mathrm{FO}$ & 4.7 Indv. & $42 / 2 n d$ & $63 / 2 \mathrm{nd}$ & 31 & $12 / 21$ \\
\hline CDT-3-10 & 25,041 & $50^{* * *}$ & 1.8 Clstr. & $17 / \mathrm{FO}$ & $27 / \mathrm{FO}$ & NA & $20 / 2 \mathrm{nd}$ & $47 / 1 \mathrm{st}$ & 25 & $15 / 27$ \\
\hline CDT-3-12 & 35,118 & 155 & 3.7 Indv. & $29 / 1^{\text {st }}$ & $56 / 1 \mathrm{st}$ & NA & $34 / \mathrm{FO}$ & $45 / 1 \mathrm{st}$ & 31 & $13 / 23$ \\
\hline CDT-3-13 & 12,881 & $38 *$ & - & - & - & 7.8 Indv. & $24 / 1 \mathrm{st}$ & $47 / 1 \mathrm{st}$ & 26 & $16 / 28$ \\
\hline CDT-3-14 & 35,039 & $100 * *$ & 3.4 Indv. & $18 /$ & $32 / 1 \mathrm{st}$ & 1.9 Indv. & $40 / 2 \mathrm{nd}$ & $49 / 1 \mathrm{st}$ & 25 & $15 / 27$ \\
\hline CDT-3-15 & \multicolumn{10}{|c|}{ N/A } \\
\hline
\end{tabular}

NA $=$ Not available

*Qbar@ Plt. Deploy

**Qbar @ FBC Jettison

CDT-3-16 and CDT-3-17, the final two tests planned for the EDU series, are scheduled to be conducted in the latter half of 2015. Following the EDU series, the qualification drops test series will commence in 2016 and extend into 2018 .

\section{A. PCDTV and MDS}

The dart-shaped PCDTV is generally used on tests in which higher stability and/or target dynamic pressures are desired. Its carrier platform is the MidAir Delivery System (MDS). The trajectories of all PCDTV tests to date are shown relative to the Critical Design Review (CDR) deployment envelopes in Fig. 2. The green, blue, and red boxes show the deployment envelopes for each of the chutes: FBCPs, Drogues, and Pilots/Mains, respectively. The dynamic pressure at Drogue deployment increases (moves to the right) as the number and/or size of programmer parachutes decreases. For example, CDT-3-1 (dark green curve) used larger programmers that resulted in a Qbar at Drogue deployment of $37 \mathrm{psf}$, at which point the $1^{\text {st }}$ stage Drogues, being smaller than the programmers, caused the vehicle to accelerate to nearly $60 \mathrm{psf}$ before

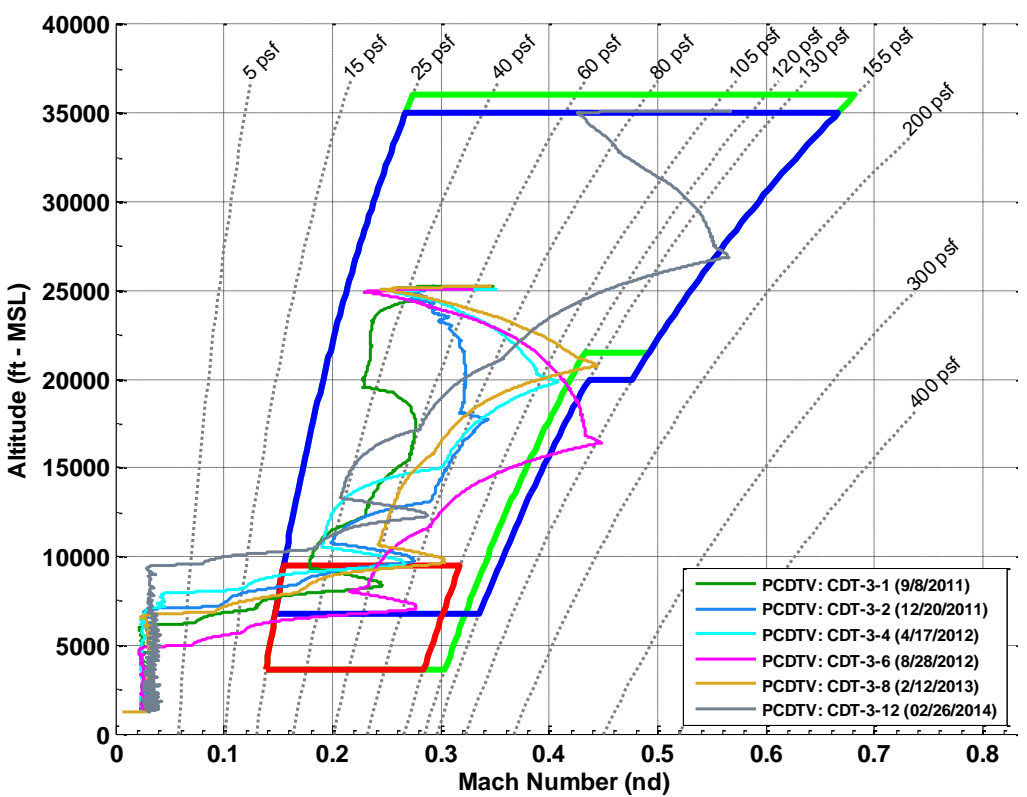

Figure 2. PCDTV Drop Test Trajectories. disreefing to $2^{\text {nd }}$ stage, and then to full open. On the other hand, CDT-3-6 (pink curve) experienced a higher Qbar at Drogue deployment as shown by the peak nearly 155 psf at Mach 0.45 due to smaller programmers. At this peak the Drogues inflated and began decelerating the vehicle to near 60 psf before the Pilots and Mains were deployed. Ref. 14 provides additional details of the PCDTV and MDS vehicles. 


\section{Developing the Test Technique: CDT-3-1 and CDT-3-2}

The first two EDU tests, CDT-3-1 and CDT-3-2, were conducted with a PCDTV and MDS from a C-130 at altitudes of 25,267 ft and 25,058 ft above Mean Sea Level (MSL), respectively. CDT-3-1 tested a nominal system, while CDT-3-2 tested two Drogues with second stage removed to conserve altitude, and a single failed Pilot and Main condition. The Mains for both tests executed the nominal disreefing schedule.

CDT-3-1 used two full open drogues as programmers to provide PCDTV control authority

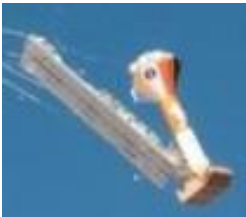

Figure 3. CDT-

3-1 Impaled Honeycomb during and after separation. Even though the release occurred at the close of the smart separation window ${ }^{28}$, the separation was nearly as expected with the PCDTV releasing with a perpendicular velocity vector relative to the MDS. An anomaly occurred when the block of honeycomb, which was added to the MDS to mitigate ground impact loads, broke its tiedowns and was impaled on the Pitot probe on the nose of the PCDTV (Fig. 3). The honeycomb eventually fell away from the PCDTV when the Main parachutes reached full open and was not used on subsequent tests. The honeycomb did not significantly affect the results of the test.

The CDT-3-2 separation also occurred at the close of the smart separation window, but unlike CDT-3-1, it was not as desired. The PCDTV pitched nearly aftend forward until it was arrested by the inflating programmer parachutes (Fig. 4), two CPAS Gen II Drogues reefed at 54\%. The programmers eventually damped the PCDTV before being cut away. The dynamics after separation did not propagate to the remainder of the test, and the desired Drogue initial state was achieved. The two-Pilot to two-Main also performed as predicted resulting in a successful test in spite of the separation anomaly.

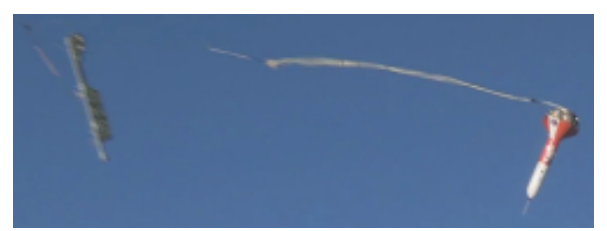

Figure 4. CDT-3-2 Pitched PCDTV at Separation

\section{Increasing Dynamic Pressure: $C D T-3-4$ and CDT-3-6}

CDT-3-4 and CDT-3-6 were the next two PCDTV tests to be performed. They were conducted with a PCDTV/MDS system from a C-130A at altitudes of 25,103 ft-MSL and 25,048 ft-MSL, respectively. The purpose of the tests was to increase the dynamic pressure at Drogue deploy by using a single reefed CPAS Gen II Drogue as a programmer parachute.

Similar to CDT-3-2, the Drogue second stage was removed on CDT-3-4, disreefing from first stage directly to full open, in order to conserve altitude. The three EDU CPAS Pilot parachutes successfully deployed three EDU Main parachutes. One of the Mains had pre-cut reefing lines to simulate a skipped second stage.

On CDT-3-6, the Drogues executed the nominal disreefing sequence, but were cut away immediately after disreefing to full open to conserve altitude. The three EDU CPAS Pilot parachutes successfully deployed three EDU Main parachutes, which executed the nominal disreefing sequence.

\section{High Dynamic Pressure: $C D T-3-8$ and CDT-3-12}

CDT-3-8 and CDT-3-12 were the final PCDTV tests to be performed during EDU testing to date. CDT-3-8 was conducted with a PCDTV/MDS system from a C-130A at an altitude of 25,187 ft-MSL. CDT-3-12 was the first and currently only PCDTV test to be performed from a C-17. The change was made so that an extraction altitude of 35,000 ft-MSL could be targeted. The actual extraction altitude for CDT-3-12 was 35,118 ft-MSL. Both CDT-3-8 and CDT3-12 were intended to obtain the high dynamic pressures at the deployment of the two CPAS EDU Drogues. To accomplish this, a cluster of three Forward Bay Cover Parachutes (FBCPs) was static-line deployed to act as programmers. Using the FBCPs also increased the number of demands on this parachute and provided drag area data though the deployment method is different than that of the flight parachutes. Both tests also staggered the Drogue mortar firing by $100 \mathrm{~ms}$. This is done on all subsequent tests which include a mortar-fired cluster of two Drogues.

On CDT-3-8, one of the Drogues inflated directly to the second stage, simulating a skipped first stage (Fig. 5). The other parachute nominally disreefed to second stage, but both were cut away without disreefing to full open in order to conserve altitude. The Pilot parachutes were deployed by mortars as the Drogues were cut away. The three EDU CPAS Pilot parachutes successfully deployed three
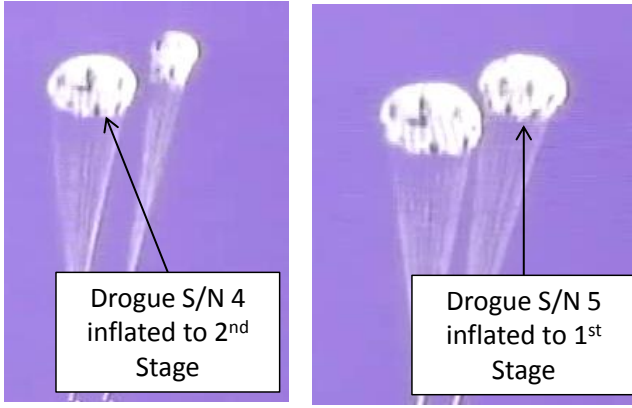

Figure 5. CDT-3-8 Drogue Skipped Stage. 
EDU Main parachutes. One of the Mains had been modified to prevent inflation, simulating a "flagging" condition. The remaining two parachutes executed the nominal disreefing sequence.

On CDT-3-12, both Drogues executed the full nominal reefing sequence. The Pilot parachutes were deployed by mortars as the Drogues were cut away. One Pilot parachute was not deployed in order to test a one-Main-out failure condition. The other two EDU CPAS Pilot parachutes successfully deployed two EDU Main parachutes. Both Mains executed the nominal reefing sequence.

For CDT-3-8, the mean ROD for the entire Main full-open phase was in family that of other two-Main tests (Table 2). During CDT-3-12 steady-state, the system experienced a pronounced pendulous motion with a period of about 14.6 seconds and an average amplitude of about 18.6 degrees from the vertical. ${ }^{29}$ A closer inspection of CDT-3-8 showed that a pendulum motion was starting to develop on that test just before touchdown. Pendulum motion under the Main parachutes is discussed further in Section III.B.3.

\section{B. PTV and CPSS}

The trajectories of all PTV tests to date are shown in Fig. 6. The PTV presents higher forebody drag than the PCDTV and therefore converges to a lower dynamic pressure for the same programmers parachutes. Because it is inherently less stable than the PCDTV, most PTV flights include programmers that provide adequate drag area to act as a control authority to damp out vehicle motion. The highest dynamic pressure was achieved during CDT-3-14 as a result of implementing a free fall phase (described below). Ref. 15 provides additional details concerning these vehicles.

1. Developing the test technique: CDT-3-3 and CDT-3-5

The first two EDU tests that used the PTV and Cradle and Platform

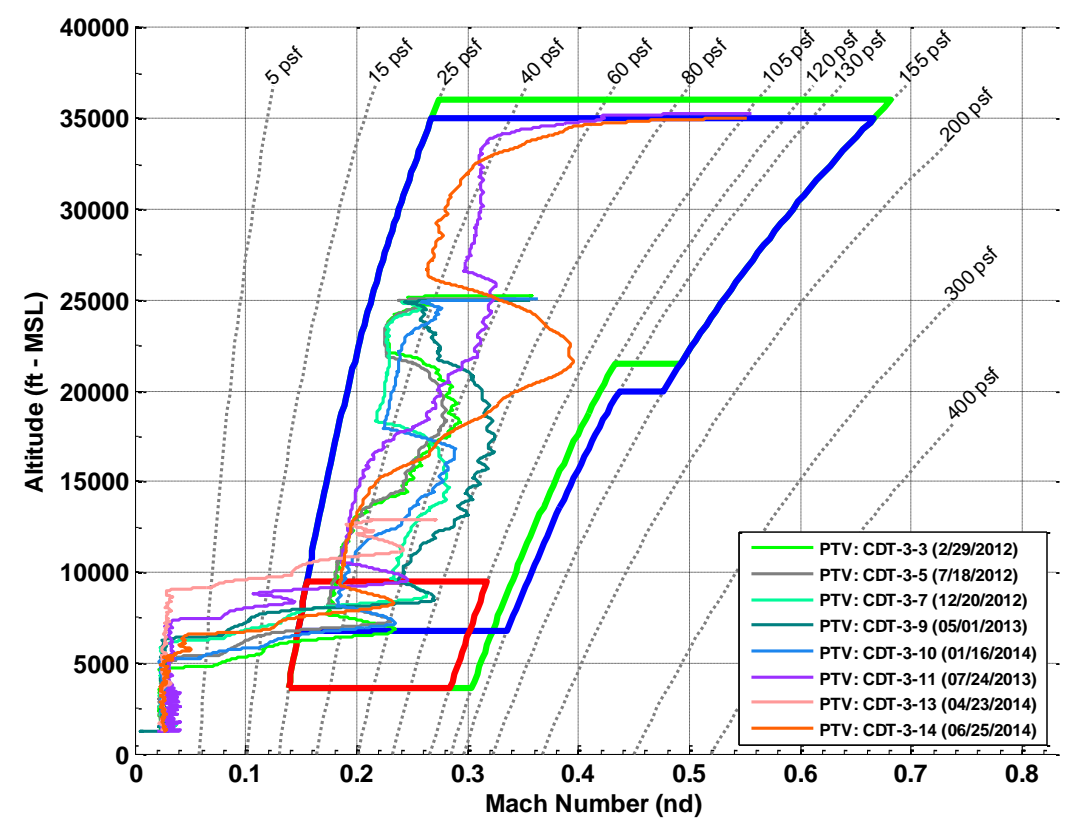

Figure 6. PTV Drop Test Trajectories.

Separation System (CPSS) were CDT-3-3 and CDT-3-5. The tests were conducted from a C-17 at altitudes of 25,249 $\mathrm{ft}-\mathrm{MSL}$ and 25,079 ft-MSL, respectively.

On both tests, the programmer parachutes (two CPAS Gen II Drogues) were deployed by static line directly to full open. The programmers were attached by a four-point harness which stabilized the PTV. The programmers were cut away simultaneously with the mortar deployment of two EDU Drogues. The Drogues completed all three stages of the design sequence. The Drogues were cut away at the same time as three EDU Pilots were mortar deployed. The Pilot parachutes deployed three EDU Main parachutes. On CDT-3-3, the Mains executed the nominal reefing sequence. On CDT-3-5, one Main had a pre-cut first stage reefing line to simulate a skipped stage condition.

Strong oscillations during the Drogue phase on CDT-3-3 caused difficulty in reconstructing the parachute inflations. It was determined that the instability was exacerbated by PTV center of gravity (CG) being on the same side of the centerline as the attach point. Therefore, the parachute compartment was rotated 180 degrees for CDT-3-5 and all subsequent tests. This reduced the PTV dynamics to acceptable levels. Technically, CDT-3-5 was a "re-test" because CDT-3-3 data was spurious.

\section{Single Drogue: $C D T-3-7$ and $C D T-3-9$}

CDT-3-7 and CDT-3-9 tested a one-Drogue-out failure scenario. The tests were conducted from a C-17 at altitudes of 24,990 ft-MSL and 24,988 ft-MSL, respectively. The complexity was increased between CDT-3-7 and CDT-3-9 by moving from two to one programmer handing off to a single Drogue, increasing the dynamic pressure at Drogue deployment.

Upon PTV/CPSS separation, the programmer parachutes (CPAS Gen II Drogues) were deployed by static line directly to full open. The programmers were cut away simultaneously with the mortar deployment of one CPAS EDU 
Drogue. The CDT-3-7 Drogue opened directly to second stage and the CDT-3-9 Drogue executed the nominal reefing schedule. The Drogue was cut away based on updated Smart Drogue Release (SDR) logic, which triggered when body rates were minimal and the pitch rate was positive. ${ }^{10}$ At Drogue cut away, three EDU Pilots were mortar-deployed. The Pilot parachutes deployed three EDU Main parachutes, which executed the nominal reefing schedule and a skipped first stage condition for CDT-3-7 and CDT-3-9, respectively.

\section{Extraction at 35,000 ft-MSL: CDT-3-11}

In order to obtain test points higher on the required deployment envelope, CDT-3-11 and two subsequent tests (CDT-3-12 and CDT-3-14) were executed at a nominal extraction altitude of $35,000 \mathrm{ft}-\mathrm{MSL}$. It was desired to extract all subsequent tests from the higher altitude, but footprint and hardware failure concerns caused both CDT-3-10 and CDT-3-15 to be dropped from 25,000 ftMSL instead. CDT-3-11 was executed from a C-17 at an altitude of 35,264 ftMSL.

On CDT-3-11, the programmer parachutes (two CPAS Gen II Drogues) were static line deployed and inflated to a permanently reefed condition (approximately 70\%). The programmers were cut away based on Smart Programmer Release (SPR) avionics. After a planned brief $(150 \mathrm{~ms})$ freefall, two CPAS EDU Drogues were deployed with $100 \mathrm{~ms}$-staggered mortar firings for the first time on a PTV and proceeded through the nominal disreef sequence. This is

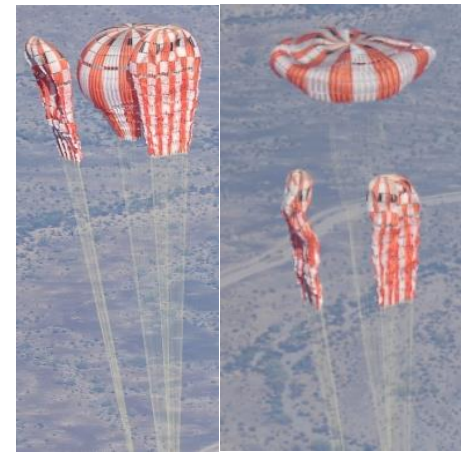

Figure 7. CDT-3-11 Main Skipping then Release. done on all subsequent PTV tests which include a mortar-fired cluster of two Drogues. The Drogues were cut away based on SDR logic. At the same time, three EDU Pilots were mortar-deployed, and they deployed three EDU Main

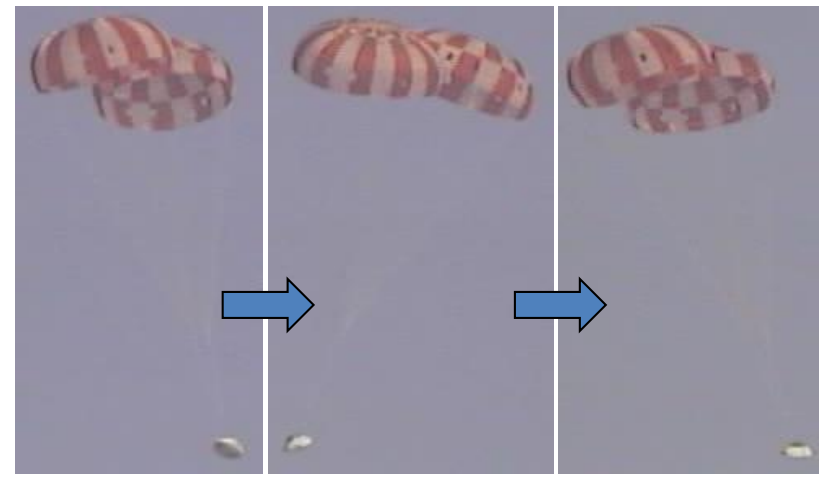

Figure 8. CDT-3-11 Main Observed Pendulum Motion. parachutes. One of the three Mains executed a skipped first stage via pre-cut reefing lines and was cut away eight seconds after Pilot mortar fire (Fig. 7). The remaining two Mains executed the nominal reefing schedule.

The PTV \& Mains exhibited "pendulum" motion which degraded steady-state performance (Fig. 8). This motion was observed on previous tests. However, the extreme motion on CDT-3-11 prompted the creation of an action team to determine the root cause and propose mitigations. The investigation is still in work and includes wind tunnel tests, subscale drop tests, and a preliminary design modification implemented on CDT-3-15.

\section{Straight-to-Mains: CDT-3-13}

CDT-3-13 was intended to test an abort scenario in which the Drogues would not be deployed, but instead the Pilots would be the first parachutes to deploy. This is referred to as a "straight-to-Mains" scenario, which may occur on some types of flight aborts. Because of the unusual configuration and the need to deploy the Mains within their deployment box, the test was executed at a lower altitude, 13,000 ft-MSL. A primary object of this test was to observe the Pilot and Main deployment at a relatively shallow flight path angle.

At extraction from the aircraft, a Mid-Air Release Mechanism (MARM) was planned to reposition the extraction parachutes from a single attach point on the bottom aft to a four point attach higher up on the CPSS. Due to a hardware failure, the reposition did not occur; instead, the extraction parachutes were released, static line deploying the recovery parachutes while the PTV was still on the CPSS. Despite this failure, the PTV separated with low body rates and maintained a stable orientation (Fig. 9) throughout deployment and inflation to full-open of the programmer parachutes, two CPAS Gen II Drogues. This allowed the rest of the test to progress smoothly and meet all primary

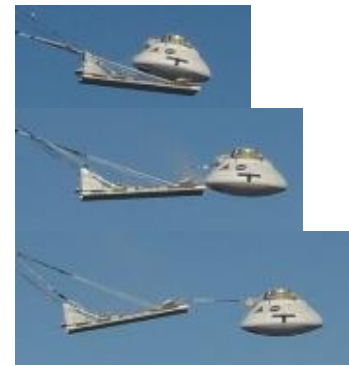

Figure 9. Stable PTV Orientation through Off-Nominal Reposition. test objectives. 


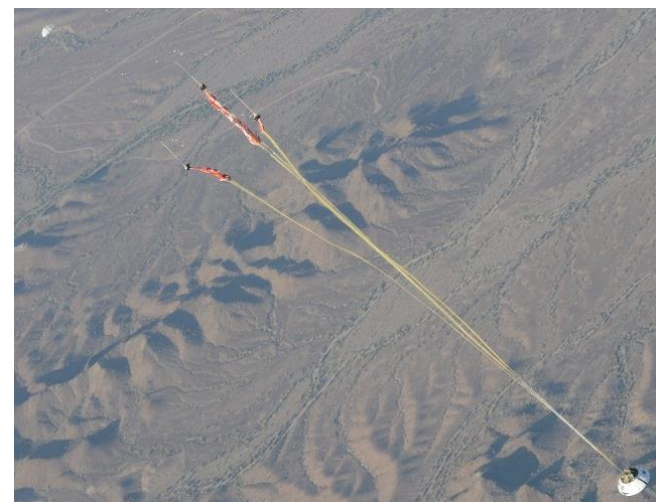

Figure 10. Off-Nominal Flight Path Angle Deployment of Main Parachutes.

The programmers were cut away based on SPR. At the same time, three EDU Pilots were mortar-deployed, and they deployed three EDU Main parachutes. The Mains successfully deployed at an off-nominal flight path angle as expected (Fig. 10) and executed the nominal reefing schedule.

\section{Forward Bay Cover Tests: CDT-3-10 and CDT-3-14}

Two tests that included jettisoning a Forward Bay Cover (FBC) from the PTV have been conducted: CDT-3-10 and CDT3-14. The tests were executed from a C-17 at altitudes of 25,041 ft-MSL and 35,039 ftMSL, respectively. CDT-3-10 was originally intended to be extracted from $35,000 \mathrm{ft}$ (already successfully demonstrated earlier on CDT-3-11), but was moved to $25,000 \mathrm{ft}$ due to issues with loads on the hardware at the high-altitude extraction.

The CDT-3-10 separation was nominal and deployed two Gen II drogues as programmers. CDT-3-14 experienced a reposition failure similar to that on CDT-3-
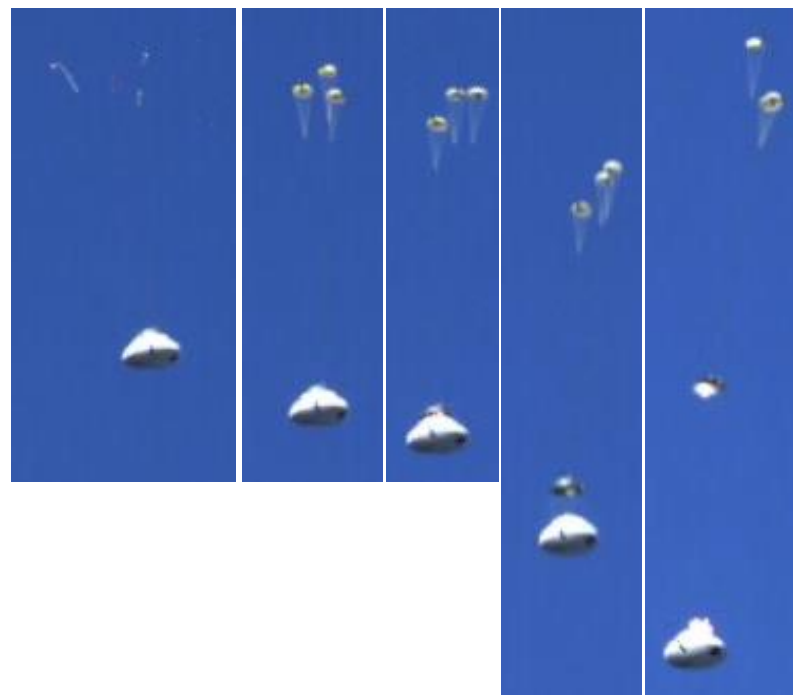

Figure 12. CDT-3-10 FBCP Deployment and FBC Jettison.

13. Unlike CDT-3-13, the CDT-3-14 PTV pitched apex forward

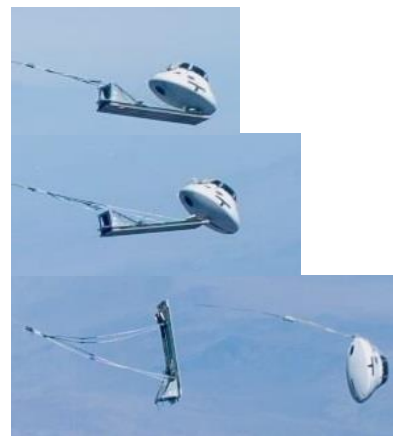

Figure 11. CDT-3-14 Apex Forward PTV Separation. before the programmer parachutes righted the vehicle (Fig. 11). The programmers provided sufficient control authority to damp the vehicle dynamics prior to release based on SPR avionics. Programmers on both tests inflated to a reefed condition before disreefing to full open.

The FBCPs were mortardeployed almost immediately after SPR for CDT-3-10 (Fig. 12), while CDT-3-14 included a 10 second free-fall to increase dynamic pressure prior to $\mathrm{FBCP}$ deployment. New avionics software was developed to deploy the FBCPs early should the PTV display increasing instability.

For both tests, the FBC was jettisoned via thrusters following a delay to allow for FBCP inflation. After a brief (about 1 second) freefall, two EDU Drogues were deployed and proceeded through the nominal disreef sequence. The Drogues were cut away based on SDR logic. At the same time, three EDU Pilots were mortar-deployed, and they deployed three EDU Main parachutes. On CDT-3-10, the Mains executed the nominal reefing schedule. On CDT-3-14, one Main had a pre-cut second stage reefing line to simulate a skipped stage condition, while the other two executed the nominal reefing schedule (Fig. 13).

\section{Main Parachute Pendulum Mitigation: CDT-3-15}

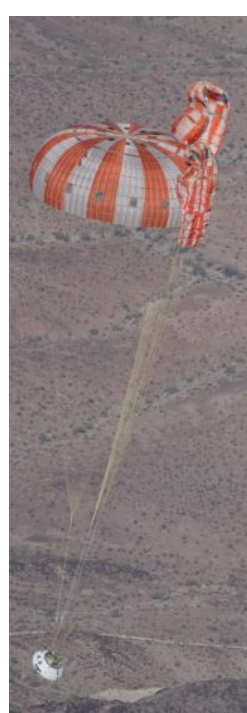

Figure 13.

CDT-3-14

Skipping Main.

CDT-3-15 was originally planned to be executed from 35,000 ft-MSL; however, as on CDT-3-10, the extraction altitude was reduced to 25,000 ft-MSL due to hardware load concerns. The test occurred in December 2014.

The primary test objective was to assess Main parachute design changes intended to address the pendulum problem seen on previous tests. Since pendulum effects are exacerbated when a parachute out condition occurs, a cluster of two Mains was tested. Each riser was reduced in length by $96 \%$ and an over-inflation control line was added to the skirt. 
Extraction and separation performed as planned. Upon separation, the programmer parachutes (two CPAS Gen II Drogues) were static line deployed and inflated to a $70 \%$ reefed condition prior to disreefing to full open. The programmers were cut away based on SPR avionics. Two CPAS EDU Drogues were deployed with staggered mortar firings and proceeded through the nominal disreef sequence. The Drogues were cut away based on SDR logic. At the same time, two EDU Pilots were mortar-deployed, and they deployed two EDU Main parachutes. The Mains executed the nominal reefing schedule.

Visual observations and preliminary data show that the test exhibited pendulum motion despite the implemented modifications. The amount of pendulum motion will be assessed when video and avionics data is available. A complete analysis had not yet been performed prior to submission of this paper.

\section{Improvements in CPAS Parachute Analysis}

\section{A. Aircraft Extraction}

One of the key differences between a CPAS flight test and an Orion flight is the delivery of the vehicle into the atmosphere. CPAS tests are conducted by extracting a mated PTV/CPSS or PCDTV/MDS out of a carrier aircraft, such as a C-130 or C-17. The extraction and separation events creates conditions that are different from those experienced by a capsule during re-entry. When reconstructing a test, adjustments are made to the simulation inputs using the best estimate trajectory information. From there fine tuning of additional parameters such as extraction parachute inflation and the induced pitch rate on the mated vehicle are performed.

An aircraft ramp contact model was developed and incorporated into the original CPAS parachute simulator, DSS Application (DSSA), a Decelerator Systems Simulation (DSS) derived simulation. DSSA is used by the Army as well as the CPAS test team to predict the dynamics and trajectory of a payload extracted from an aircraft during the beginning of the EDU series. DSSA was replaced by the Automatic Dynamic Analysis of Mechanical Systems (ADAMS) simulation. ADAMS was used by the Ares program and was adapted for CPAS. ${ }^{6}$ PTV state information at programmer deployment line stretch is provided from the ADAMS simulation and used as initial conditions for the FAST simulation. Taking the condition at this point rather than at separation, coincides with PTV avionics system activation. This is the point from which all subsequent parachute release events from the PTV start.

PTV/CPSS reconstructions are a challenge, especially during the pitch-up motion of the mated vehicle prior to separation. Before CDT-3-10, the preflight Monte Carlo analysis bounded previous test experience using the delayed load transfer technique. However, following the deployment of the backstop reposition technique on CDT-3-10, the post flight review indicated that the preflight smart separation predictions were not adequately bounded within smart separation window. As a result a combination of reconstruction approaches and a higher fidelity reposition model were developed. One method introduced a time-varying collector force which varied the tension (axial force) in the extraction line and the position of the extraction parachute until a good flight correlation was
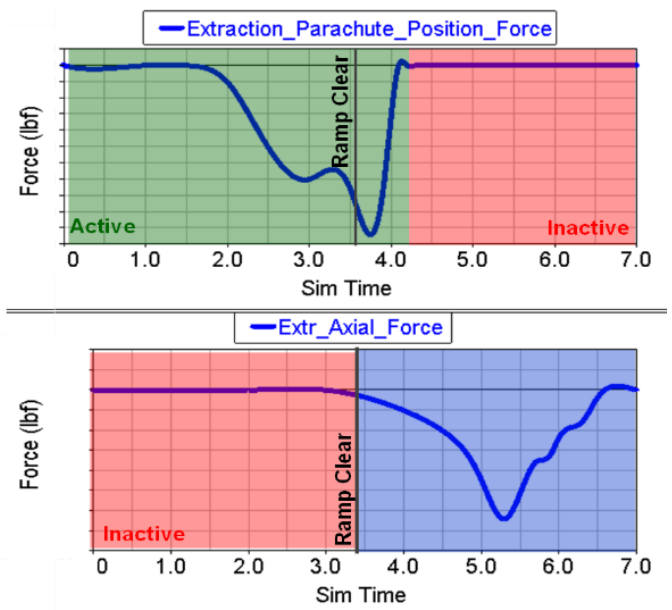

Figure 14. Active and inactive regions of positional and axial forces.

reached (Fig. 14). While this model provided an acceptable reconstruction, the solution was unique to CDT-3-10. The drawback to this approach is the unrealistic line load predictions post-reposition.

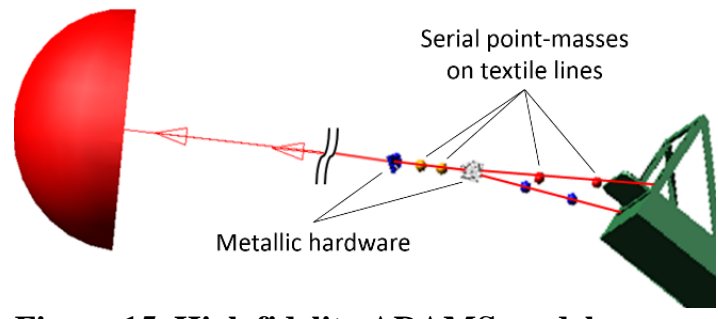

Figure 15. High fidelity ADAMS model.

The higher fidelity model better represents the elements in the extraction load train by using Computer Aided Design (CAD) models of the metallic hardware and serial pointmasses connected by spring-damper forces for the textile lines (Fig. 15). The serial point-masses decelerated the predicted system deployment sequence as witnessed in flight. This model is currently being refined to produce representative dynamic peak loads to reduce the probability of line segment and hardware malfunctions, while maintaining a solid dynamic pitch plane motion prediction. ${ }^{30}$

American Institute of Aeronautics and Astronautics 


\section{B. Independent Parachute Modeling}

There are two methods CPAS used during EDU testing to model parachutes: as a single composite parachute and as multiple individual parachutes using an independent parachute model. The DSS was used as the primary tool for previous generations and early EDU testing (CDT-3-1 through CDT-3-9). Though it was a composite parachute model, updates during early the EDU series allowed independent parachute $\mathrm{C}_{\mathrm{D}} \mathrm{S}$ reconstructions, though loads continued to be composite. CPAS then adopted the Flight Analysis \& Simulation Tool (FAST), an independent parachute model, to more accurately model parachute cluster effects. This allowed the project to eliminate the conservative load sharing assumption when establishing the canopies' design limit loads. FAST started as a post-flight reconstruction tool as comparisons were done with DSS and quickly transitioned to being the secondary preflight simulation tool from CDT-3-6 through CDT-3-9. It then became the primary preflight trajectory simulation starting with CDT-3-11 (including CDT-3-10 which flew after CDT-3-11).

All EDU reconstructions were performed using the DSS or FAST individual parachute capabilities. ${ }^{11}$ This allows for modeling the variability between parachutes in a cluster, such as differences in opening parameters, timing, and drag coefficient, which greatly improves the ability of the simulation to match flight data precisely. It also increased the number of data points that define the parachute inflation parameter dispersions allowing the move towards statistical distributions. ${ }^{7}$

Independent parachute modeling with FAST also allowed the advancement of other models such as time-varying $\mathrm{C}_{\mathrm{D}}$, skipped stage, and torque as well as updates to the reconstruction process.

\section{Time-Varying $\mathbf{C}_{D}$ Model}

The use of an independent parachute model allowed for the creation of a time-varying $C_{D}$ model. ${ }^{31}$ After the Main parachutes inflate to full open, the system decelerates to an equilibrium velocity, however there is some oscillation about this velocity due to cluster dynamics. These dynamics are dominated by the canopy fly-out angles, which affect the riser torque, projected area, and effective drag coefficient. A time-varying $C_{D}$ model was developed by E. Ray to represent the effects of the Main parachute dynamics. ${ }^{31}$ This model is based on the observed coupling of fly-out angles, projected areas, and sudden losses of drag area due to canopy collisions, as illustrated in Fig. 16. Cluster behavior changes from an initial transient epoch to a damped epoch, due to the added porosity of the Mains. However, not all flight tests were able to obtain data for each parameter for both epochs. Each test was reconstructed adequately, but the total sample set is relatively small. Therefore, dispersed Monte Carlo simulations will exhibit behavior outside CPAS experience. Further testing and data analysis should act to restrict these interactions.

The strong pendulum motion observed on CDT-3-11 increased the peak rate of descent. Because it was an asymmetric effect, this behavior cannot be replicated in the current model. A more complex model of individual canopies interacting in a cluster is being investigated. ${ }^{29}$

\section{Skipped Stage Modeling}

CPAS has changed the method in which skipped stages are modeled because of the increased capability when using an independent parachute model. This capability, along with data obtained from skipped stage flight tests, has been crucial in modeling the behavior of a skipping canopy as well as the crowding effect on non-skipping ("lagging") neighbors. For the finite mass inflation of CPAS Main parachutes, the cluster is assumed to inflate nominally through the nominal fill time, at which point the skipping parachute continues inflating. This sub-phase modeling method was used to reconstruct three flight tests involving skipped stages. Best fit inflation parameters were determined for both the skipping and lagging canopies ${ }^{8}$

American Institute of Aeronautics and Astronautics 
As of CDT-3-14, CPAS treats a skipped second stage as a single continuous event. This is consistent with peak load observations from CDT-3-4 and MDT-2-2. These tests used a pre-cut reefing line. However, CDT-2-1 experienced an unplanned skipped second stage due to a failure of the reefing system while under tension and was best modeled as a staged event. The reefing system hardware design has since been modified to prevent this failure.

\section{E. Main Parachute Torque Modeling}

While under the Main parachute cluster stage, a moment is imparted on Orion from the Main parachutes based on the relative riser twist angle, $\phi$. This torque will affect Orion's roll angle, which is controlled by Reaction Control System (RCS) thrusters to provide a favorable orientation at splashdown. RCS capabilities to counteract moments are limited, and a requirement has been placed on CPAS to limit the amount of torque induced by the Main parachutes. A conservative model for riser twist induced torque was developed by V. Drozd at Airborne Systems through

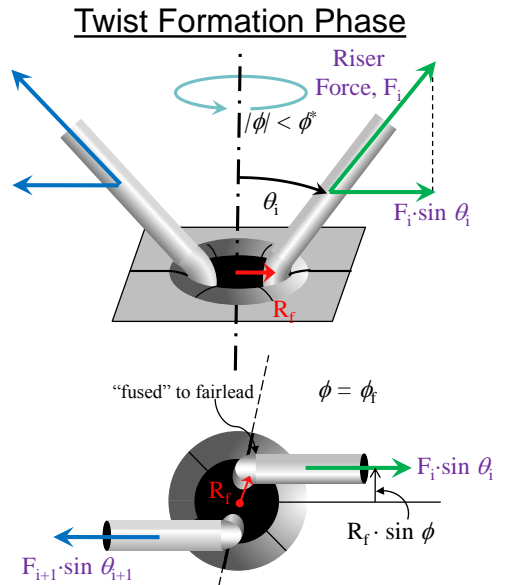

Figure 17. CPAS Twist Torque Model. analytical methods and refined through full-scale ground experiments. The model provides a way for integrated vehicle analysis to ensure that torque requirements are met.

The model (Fig. 17) first estimates the "twist formation" torque generated by friction between the riser and the edge of the fairlead as the vehicle rotates. Once a critical twist angle $\left(\phi^{*}\right)$ is exceeded, the model transitions to the "formed twist" phase, where torque is generated by riser tension offset by the riser winding radius.

The composition of CPAS risers has changed from steel (bundles of wire rope) to textile (continuous suspension lines) over the course of EDU testing. These changes necessitated reevaluating the torque model. Since the radii of the risers are a first order input into the torque model, the new larger diameter textile risers were expected to produce different torque results. Full scale ground tests were performed to quantify these changes to the torque model. The ground test data, combined with reconstruction data, ${ }^{32}$ resulted in an improved understanding of the torque imparted on the vehicle by the parachutes. A more complex version of the Drozd model has been developed with these results which more closely predicts the torque imparted on the capsule at varying twist conditions. The earlier model successfully produced conservative results while the new model produces more accurate results. From an integrated vehicle perspective the conservative model is useful in terms of maximum RCS thruster authority required but a more accurate model is more appropriate for evaluating RCS propellant consumption.

\section{F. Load Train Monte Carlo Capability}

Load train analysis is used in the design of test support equipment. Quantifying snatch loads is necessary to provide an understanding of loads imparted to parachute deployment hardware and test vehicle structural attach points. However, the model used to determine snatch loads has limitations that must be considered when applying the loads to determine margins of safety. This model, provided at the conclusion of Gen II testing by Randy Olmstead of Airborne Systems, applies the principles of conservation of momentum and energy to compute the snatch forces from the difference in velocity between two bodies. Application of these principles assumes little significant change in the momentum or mechanical energy of the entire system over the brief time period of the snatch event. Rotational effects during the snatch are not modeled, and a constant flight path angle during the snatch event is assumed. It is intended that rotational effects will be added in the future. There are currently no plans to simulate a variable flight path angle.

Starting with CDT-3-9, a Monte Carlo capability was added to the tool to provide a more accurate representation of hardware margins of safety across all preflight trajectories. State vectors and parachute inflation loads for each Monte Carlo cycle are delivered from FAST and ADAMS, depending upon the event being assessed (mated vehicle reposition, programmer parachute deployment, or recovery system deployment). The state vector is used to calculate the delta velocity between the two bodies of interest which is then used to determine the snatch load. This load is compared to the inflation load and the larger of the two values is used to calculate the margins. Statistics are generated for every component to quantify the number of cycles and percentages that result in a positive or negative margin of

American Institute of Aeronautics and Astronautics 
safety. Finally, the load train table is populated with ICs that yield the worst case margins of safety for presentation purposes.

The snatch loads model has not been verified through testing and there are currently no plans to do so. The current snatch load model routinely over-predicts the load as determined by comparisons of energy modulator strip-out length predictions to post-test measurements, and is therefore considered to be conservative.

\section{G. Main Parachute Reefing Line Tension}

Reefing lines are an essential feature to manage inflation loads. Previous methods tracked the maximum reefing tension to the axial force ratio providing a single maximum value. During the EDU series a new method was used which required a chase aircraft staged to be level with the cluster of Main ringsail parachutes during the initial inflation and reefed stages. This allows for capturing high-quality still photographs of the reefed skirt, suspension line, and canopy geometry. The overinflation angles are determined from the photographs and are synchronized with measured loads data in order to compute the tension force in the reefing line as shown in Fig. 18. The traditional reefing tension equation assumes radial symmetry, but cluster effects cause the reefed skirt of each parachute to elongate to a more elliptical shape. This effect was considered in evaluating multiple parachutes to estimate the semi-major and semi-minor axes. The traditional method also assumed the maximum over-inflation angle, and therefore reefing tension, coincided with the peak riser load. Photographs taken during EDU testing showed that the maximum over-inflation angle was occurring after the peak riser load. The results of twelve flight tests have been assessed, three of which are published in Ref. 9. The results are dependent on the number of canopies in a cluster and whether any canopies skip a reefing stage. The computed tension has not been confirmed through any direct measurements to date. Therefore, design limits were evaluated using legacy wind tunnel reefing line measurements. ${ }^{33}$

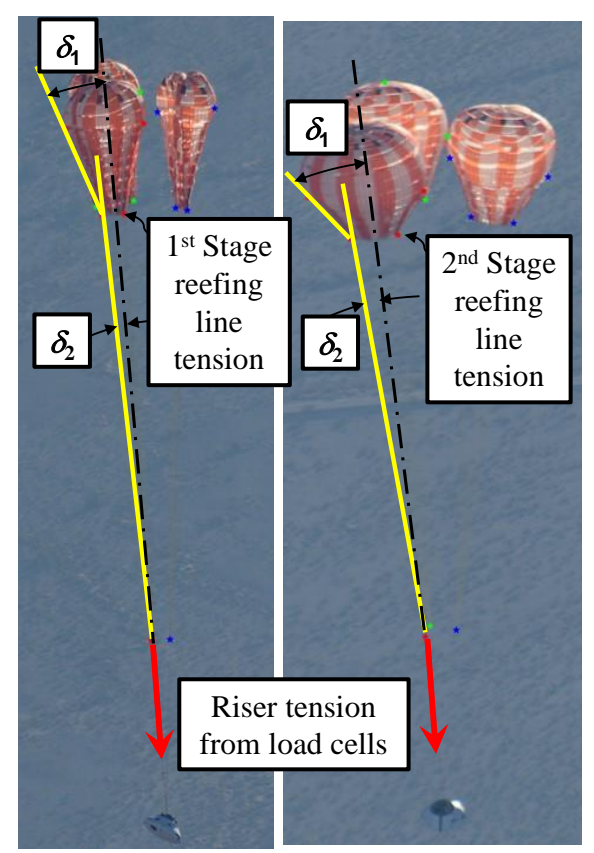

Figure 18. Estimated reefing line tension.

\section{H. Parachute Reconstructions}

In order to develop and improve a model of CPAS parachutes, attempts are made to reproduce, or "reconstruct," each test using processed instrumentation data recorded during the test. A detailed flow chart of this process is shown in Ref. 11. Various instruments measure the necessary data: position, velocity, acceleration, riser and harness loads, atmospheric conditions, vehicle mass properties, and photogrammetry. Trajectory, winds, and atmospheric data are processed into a "best estimate" data set which is combined with parachute loads and accelerometer data to provide the basis of the reconstruction. Measurement uncertainty is also propagated as data is processed into drag area, dynamic pressure, etc.

Though FAST has been used for reconstructions for all tests since CDT-3-9, several of the performance parameters can be determined directly from the test data without a simulation. These include reefing ratio, drag coefficient, and over-inflation factor. A MATLAB process was developed to reduce the amount of labor involved in a reconstruction and to reduce the subjectivity in the results. 


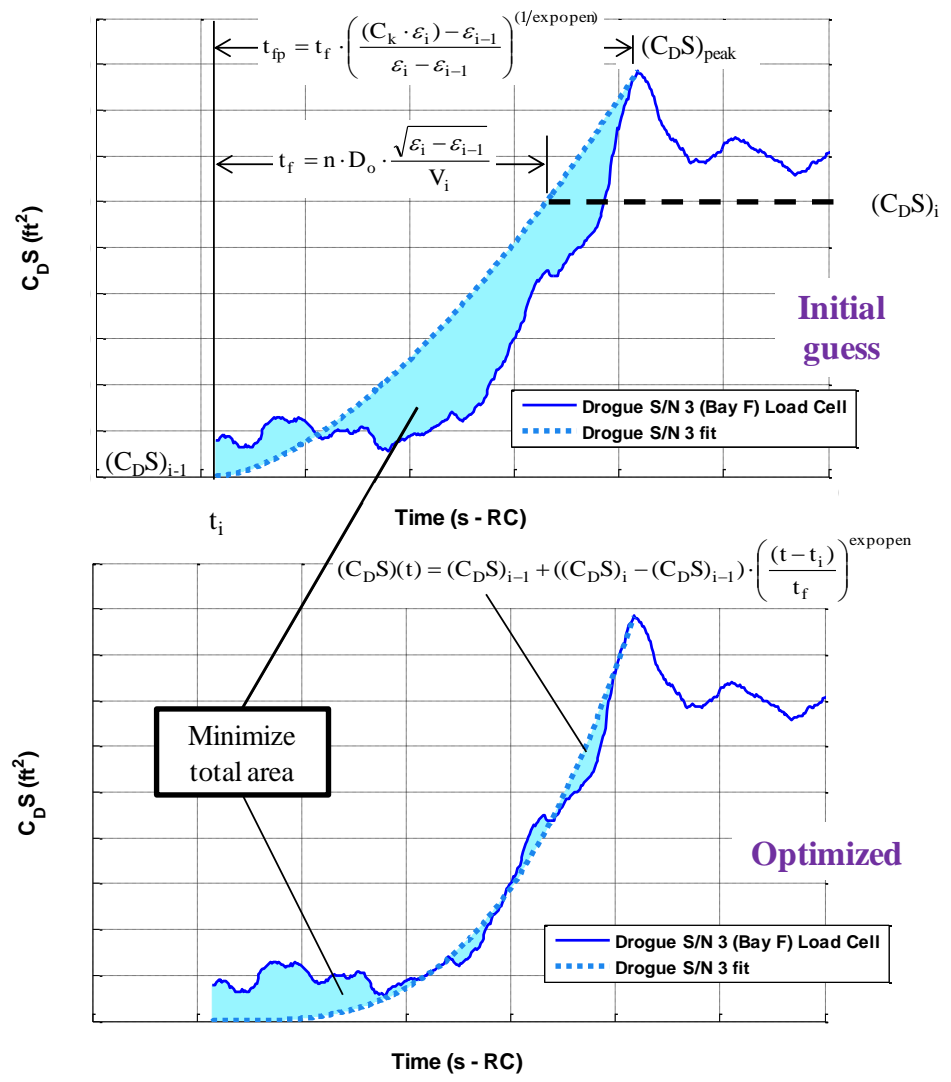

Figure 19. Infinite mass drag area growth curve fit example.
This process is discussed in detail in Ref. 11; this paper will provide an overview. Given an initial guess (e.g. from Model Memo values or from a previous reconstruction), the drag area growth curve can be modeled using basic equations. This growth curve is then optimized to best match the test data using the MATLAB "fminsearch" function to generate the inflation constants for a potential FAST input file (Fig. 19). The input file is then run in FAST and the total parachute loads are compared to the test data. The initial conditions for FAST are obtained directly from test data and computed mass properties. If a sufficient match is achieved for that stage, the process moves to the next stage. In some cases, engineering judgment is required to manually adjust the parameters for a better loads match.

It is possible to put FAST "in-theloop" to match loads directly, instead of using drag area as a proxy. This method has been used in a limited fashion to reconstruct Pilots and may be expanded to other parachutes in the future. It could eventually be used to optimize additional variables such as spring constants and added mass terms.

\section{Future of CPAS Parachute Analysis}

Though nearing the end of EDU testing, a significant amount of tests and a potential parachute redesign is ahead. A series of wind tunnel and subscale Main parachute tests are currently being completed to understand design change effects on the parachute stability and drag area in response to the pendulum motion observed. A design will be chosen at the end of testing in May for CPAS to bring to CDR currently scheduled for the fall of 2015. Two additional EDU drop tests will be completed in late 2015 or early 2016.

After EDU testing and CDR are complete, qualification testing will occur. The test matrix for this testing series is still in development, however the two EDU test vehicles, PCDTV/MDS and PTV/CPSS, will continue to be used. For the remaining EDU and qualification testing, preflight and post-flight analyses will be similar to those used to date with the potential advancements listed below.

- Update load versus elongation curves in ADAMS and the snatch loads model using pull test data currently being completed by Airborne Systems. Current model assumes a linear relationship. Preliminary pull test curves shows a quadratic relationship. This update should reduce conservatism and produce lower load predictions.

- Implement Monte Carlo sweep capability to increase the efficiency of assessing drop test variations; for example: free fall time, drag area changes, or initial altitude variations. This capability allows a single input file and a single command line prompt to run all variations as either a single nominal or Monte Carlo. This will reduce the amount of time required to set up and run the variations as well as reduce human error caused by multiple input decks.

- Implement FAST "in-the-loop" for reconstructions to further automate this process. 


\section{Conclusion}

EDU testing to date has employed the use to two test vehicles (PCDTV and PTV) and their respective extraction systems (MDS and CPSS) to test the full Orion parachute system with different failures and initial conditions. As the testing series progressed, the complexity and risk of each test increased, requiring refinements of the analysis tools used both in pre- and post-flight assessments. The ADAMS simulation was advanced for use during the extraction and separation phases of flight. The independent parachute simulation, FAST, replaced DSS to assess the test parachutes (FBCPs, Drogues, Pilots, and Mains). EDU testing experienced an increase in fidelity of parachute models including a time-varying $\mathrm{C}_{\mathrm{D}}$ model used for fly-out, rate of descent, and torque, and an update to the skipped stage model. The method of test reconstructions was also developed significantly. The process has become semi-automated but will be further improved to do reconstructions with the simulation in the loop. 


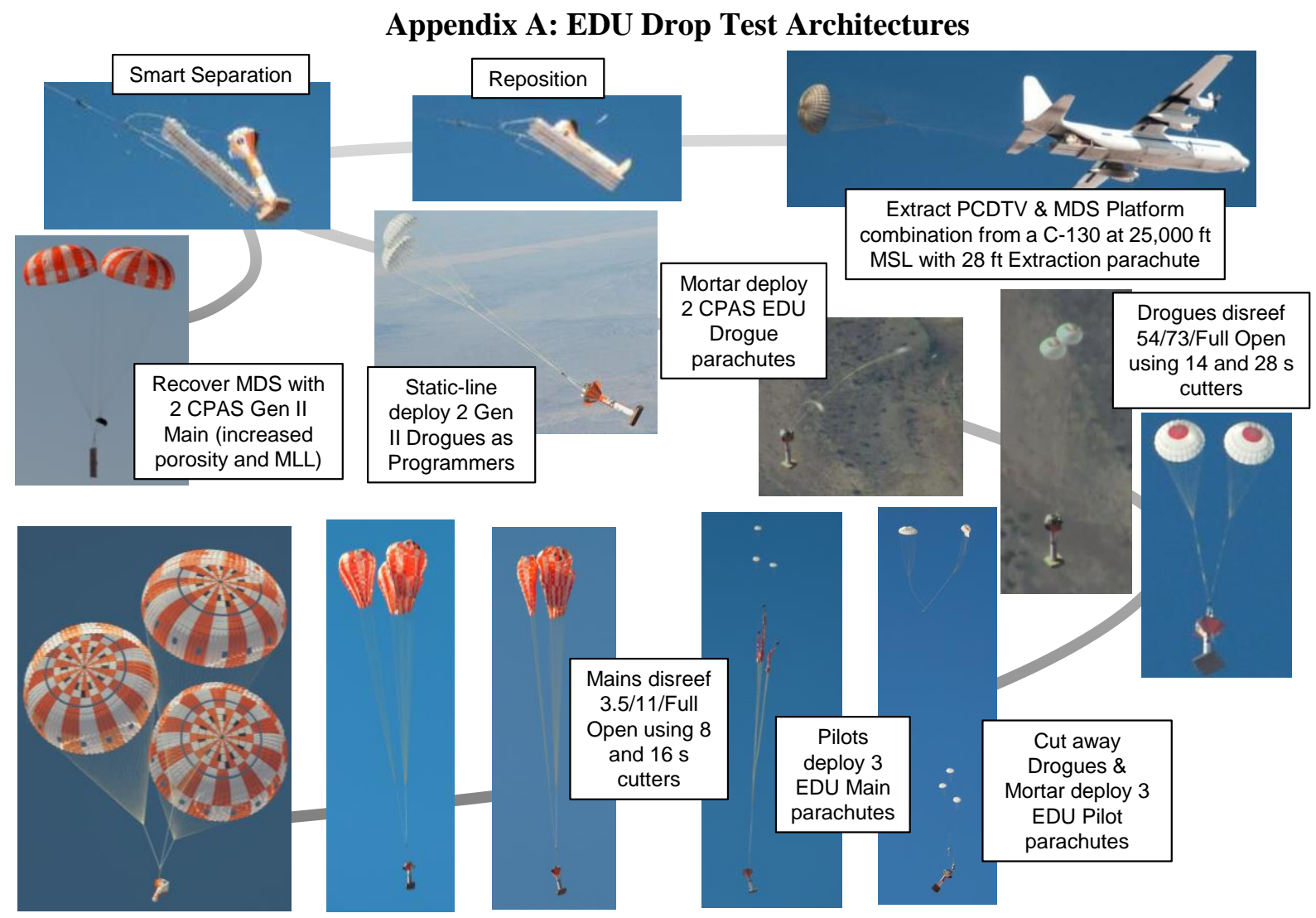

Figure 1. CDT-3-1 Test \& Simulation Architecture.

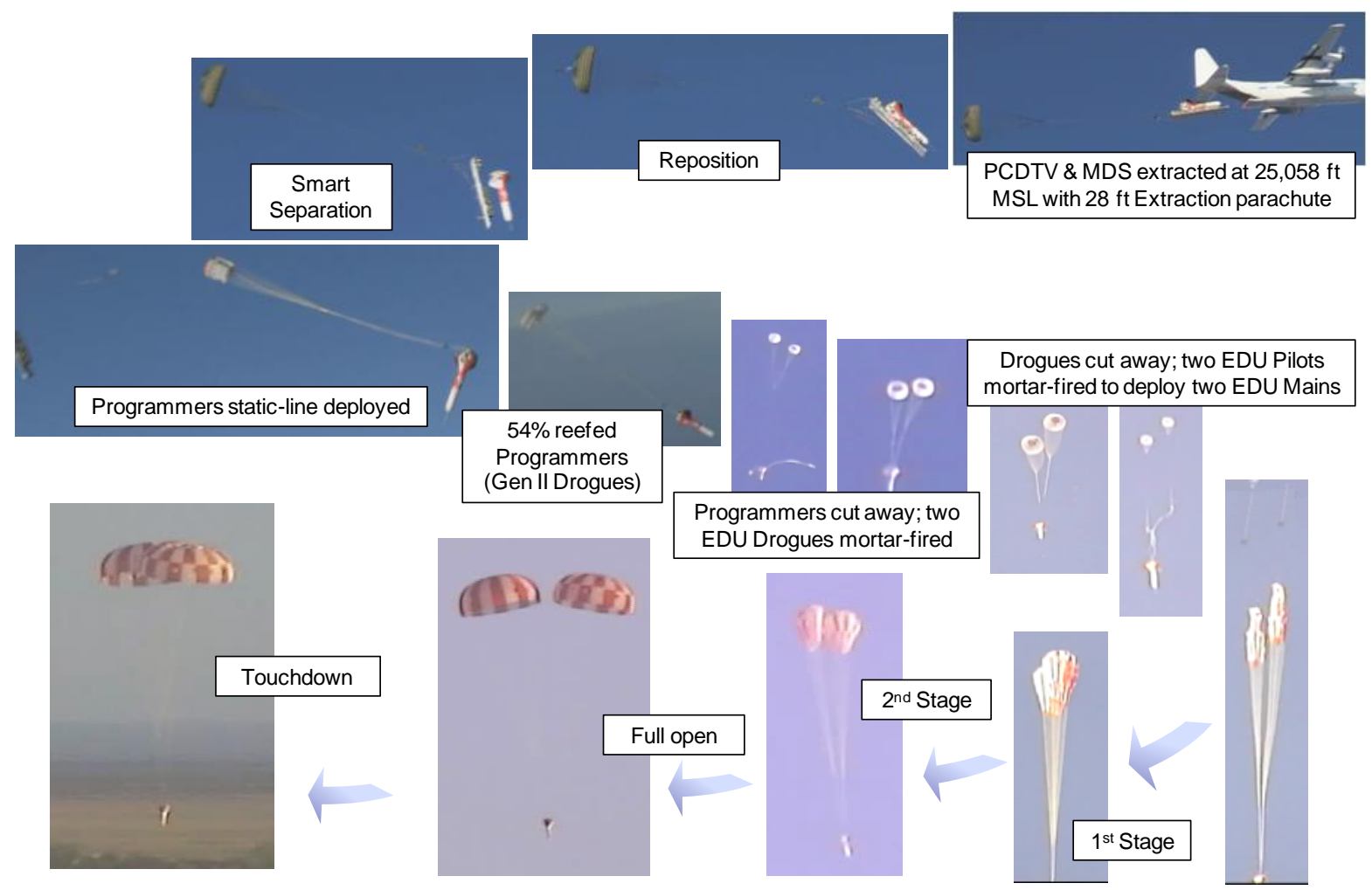

Figure 2. CDT-3-2 Test \& Simulation Architecture.

American Institute of Aeronautics and Astronautics 


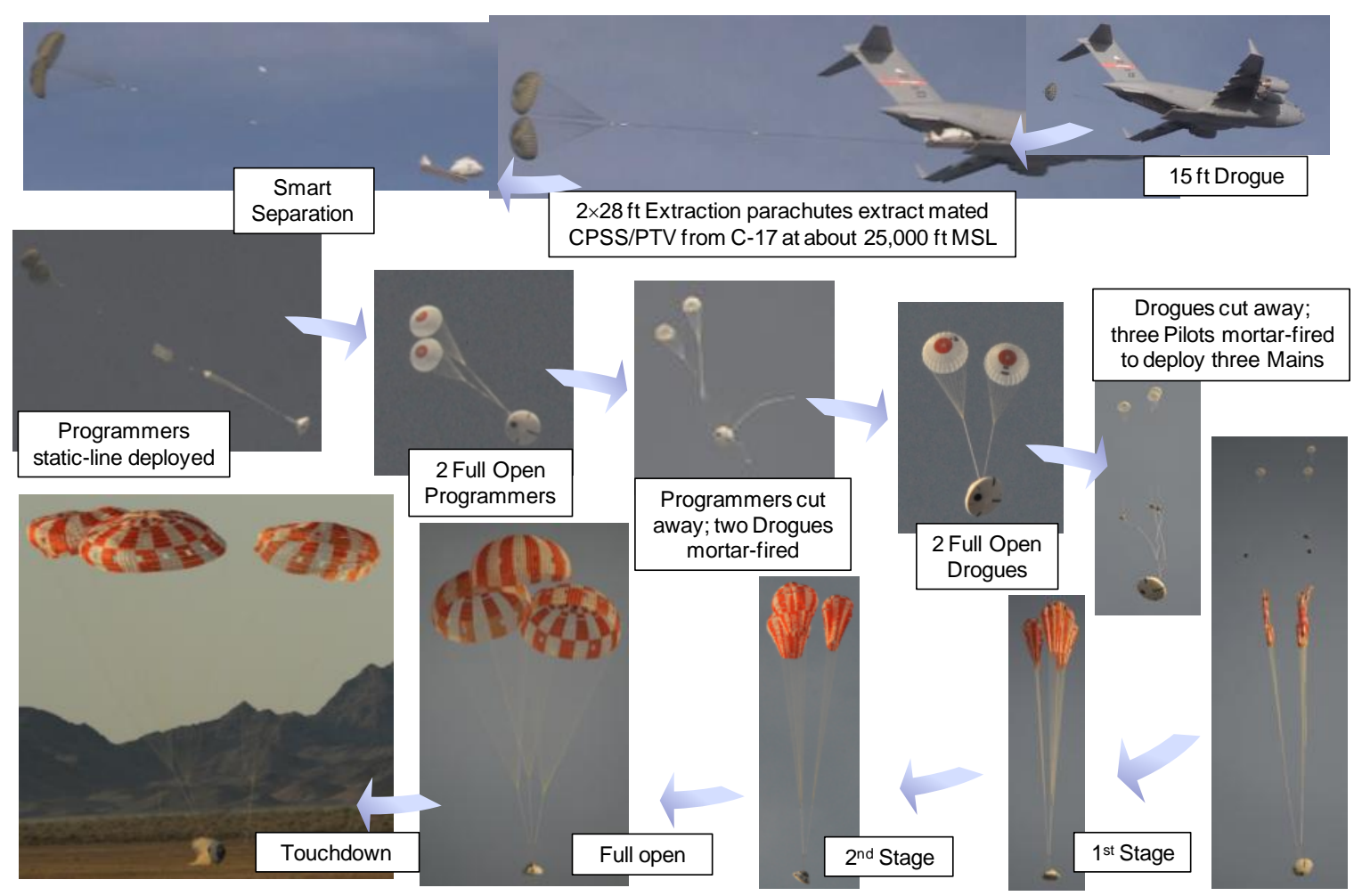

Figure 3. CDT-3-3 PTV concept of operations.

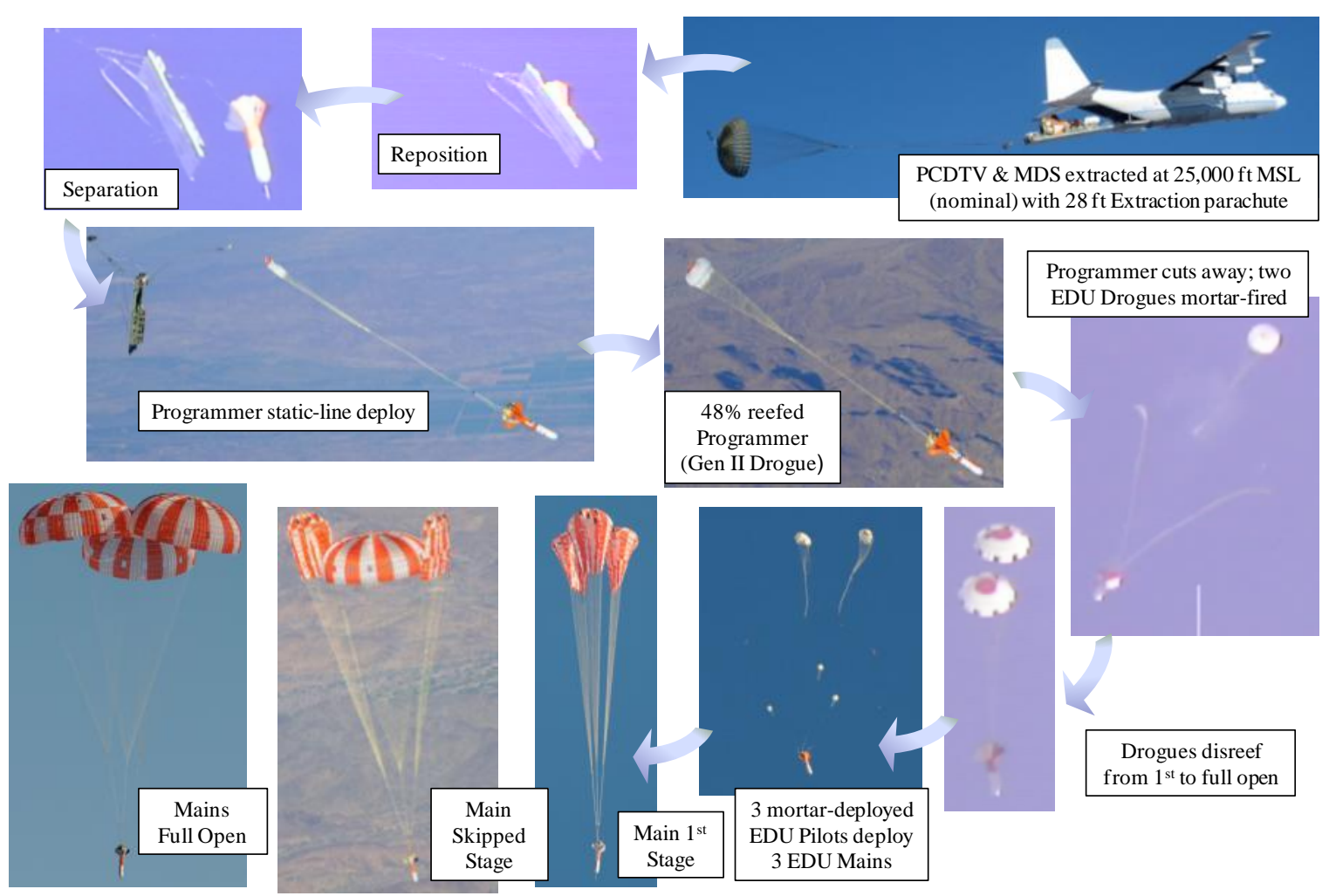

Figure 4. CDT-3-4 PCDTV concept of operations.

American Institute of Aeronautics and Astronautics 


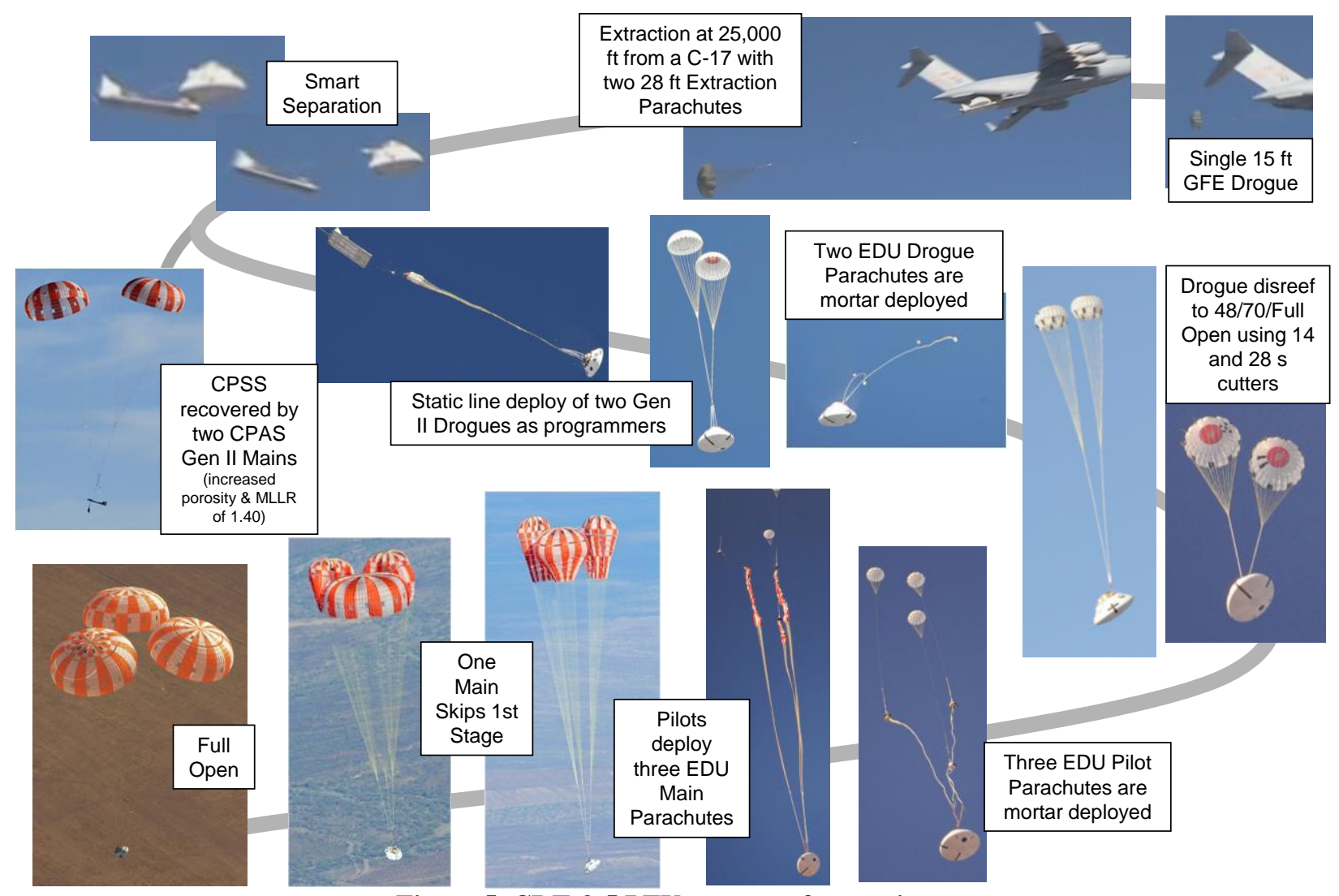

Figure 5. CDT-3-5 PTV concept of operations.

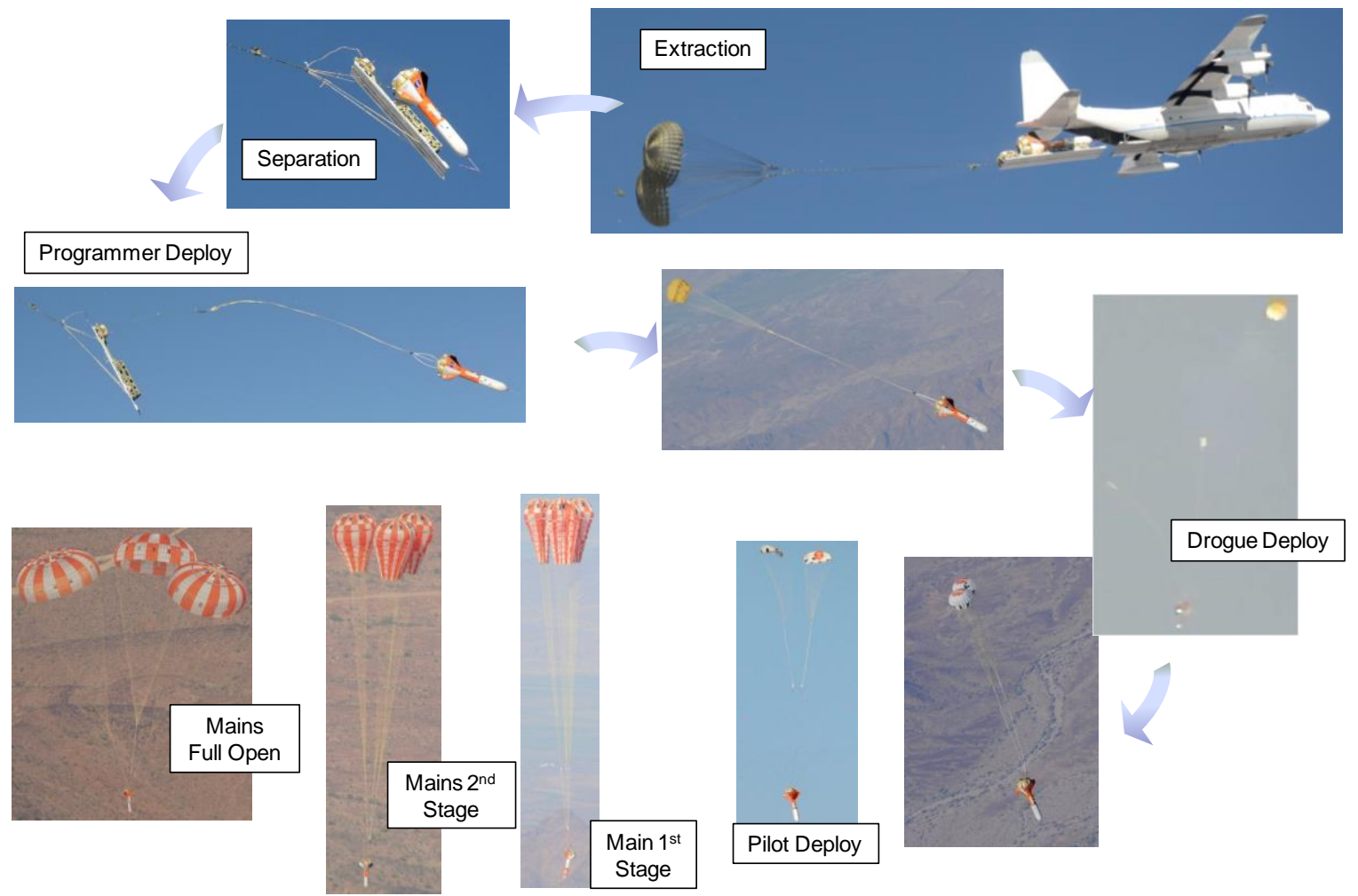

Figure 6. CDT-3-6 PCDTV concept of operations.

American Institute of Aeronautics and Astronautics 


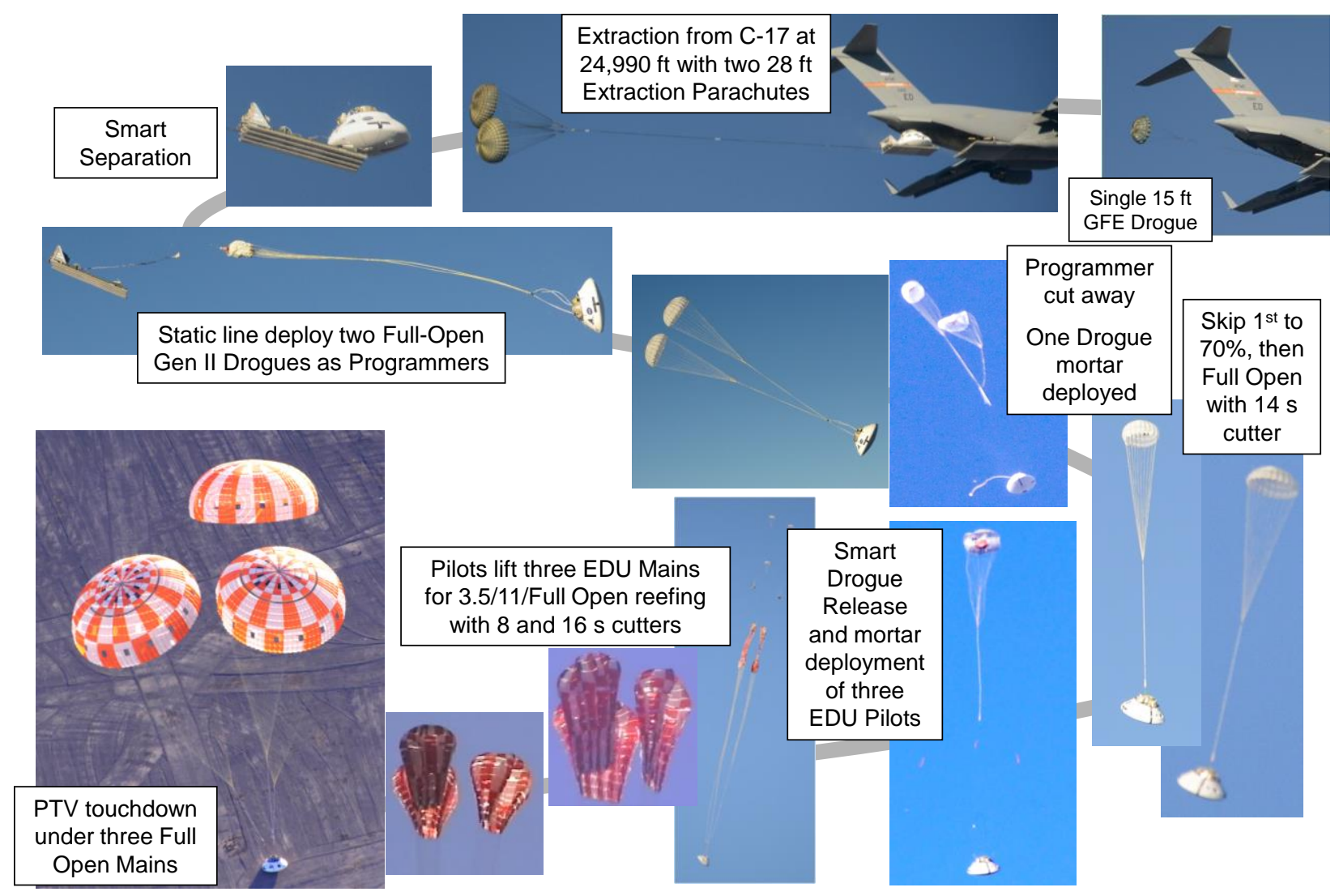

Figure 7. CDT-3-7 PTV concept of operations.

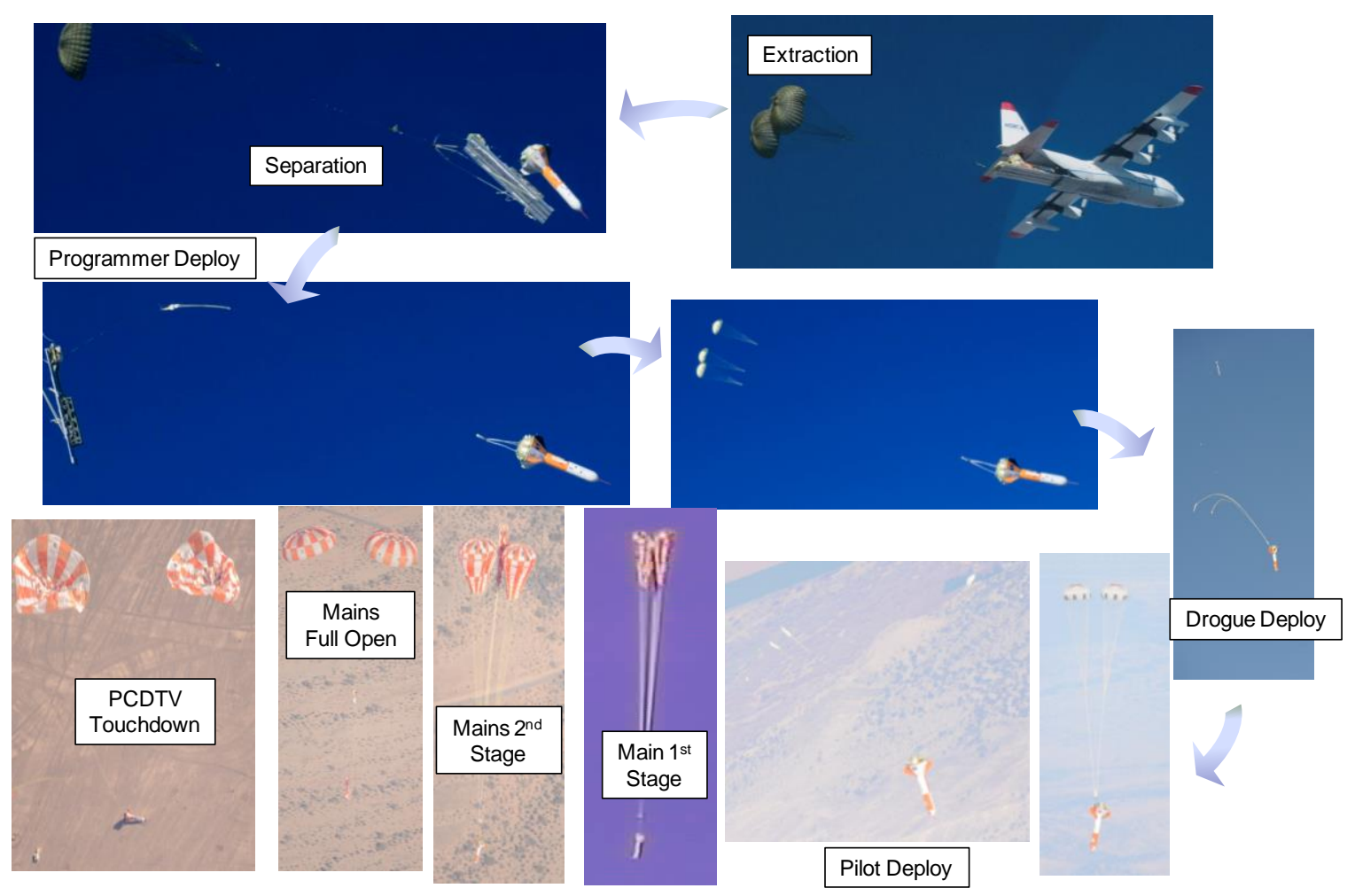

Figure 8. CDT-3-8 PCDTV concept of operations.

American Institute of Aeronautics and Astronautics 


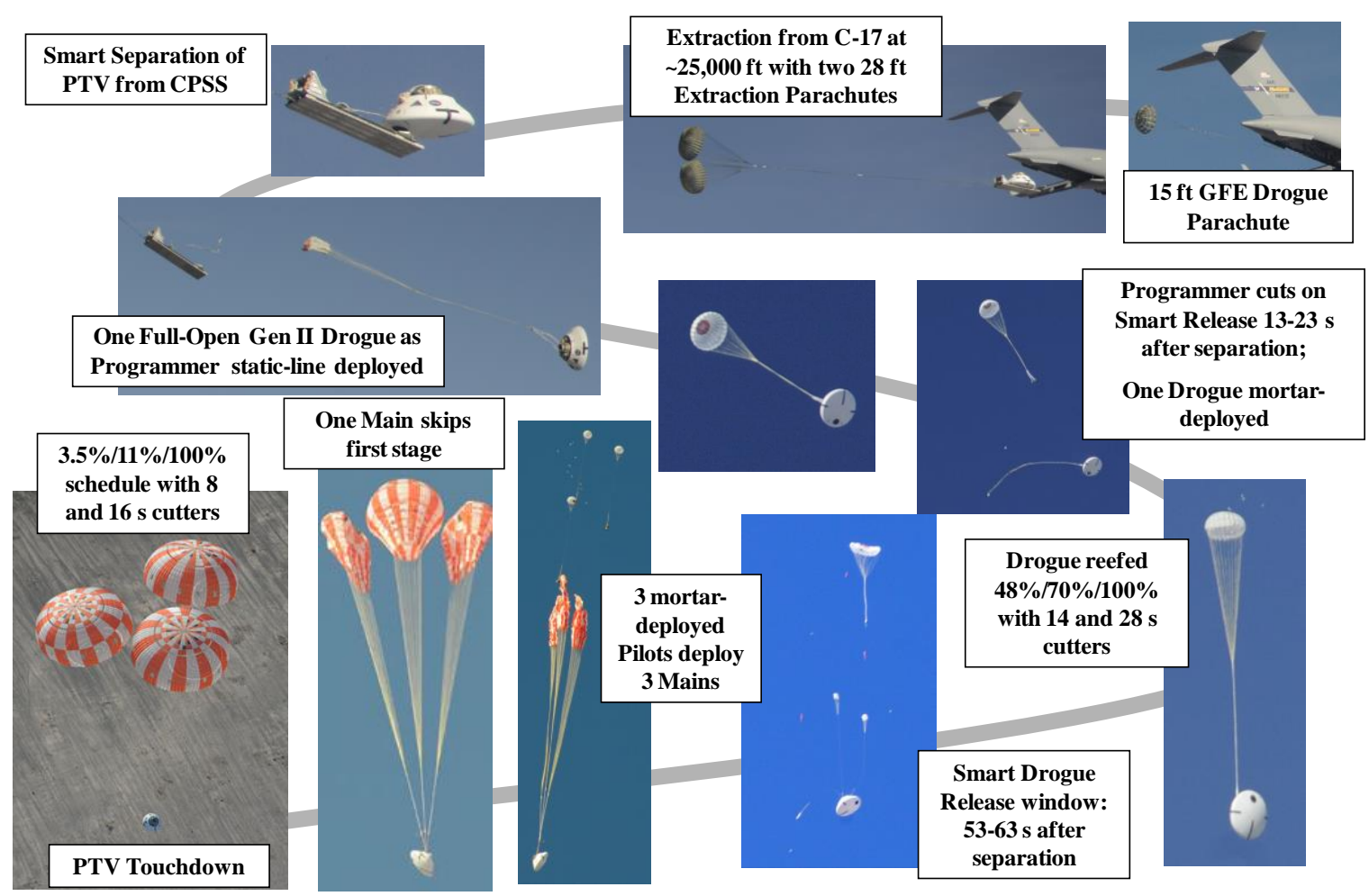

Figure 9. CDT-3-9 PTV concept of operations.

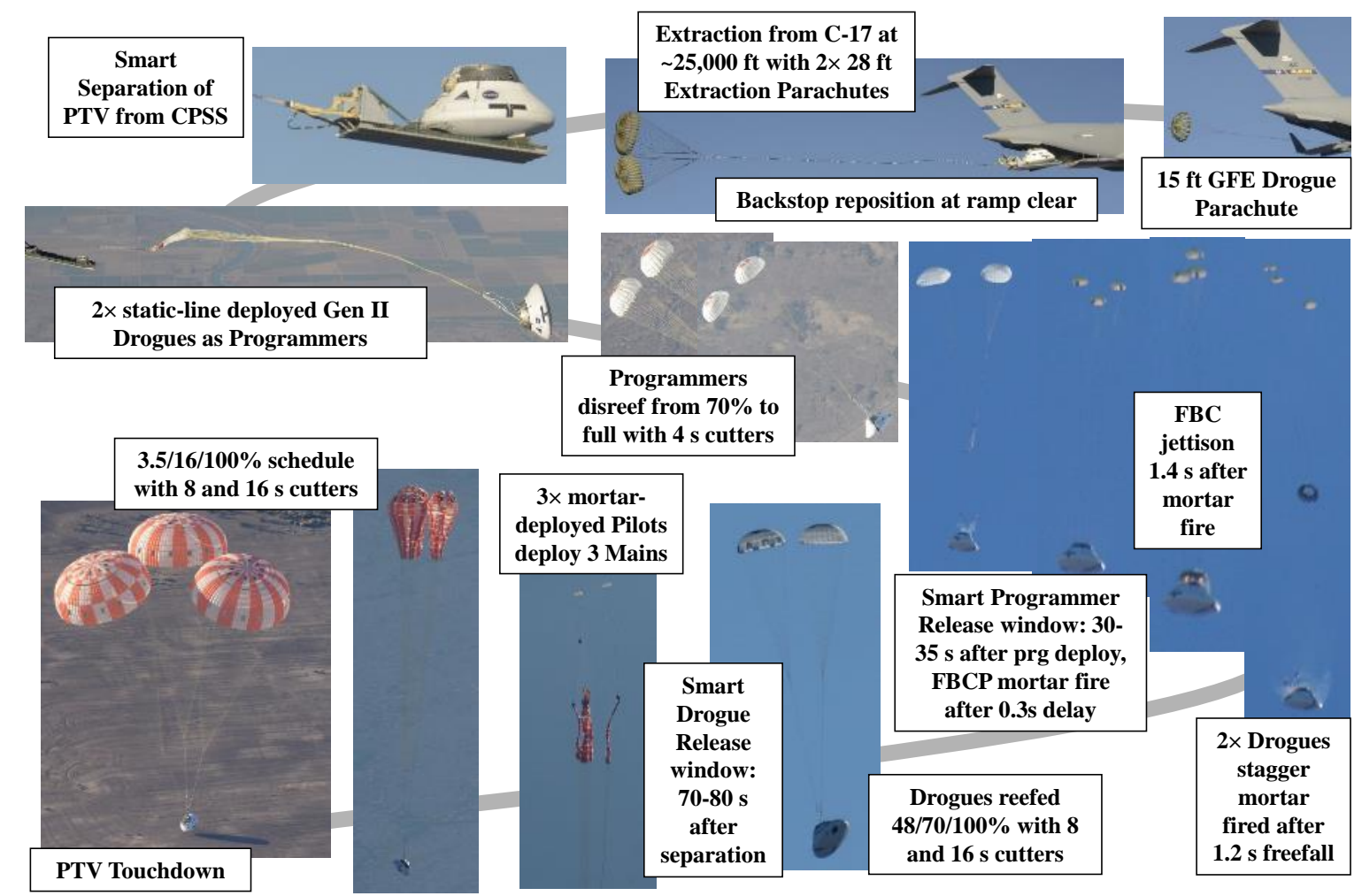

Figure 10. CDT-3-10 PTV concept of operations. 


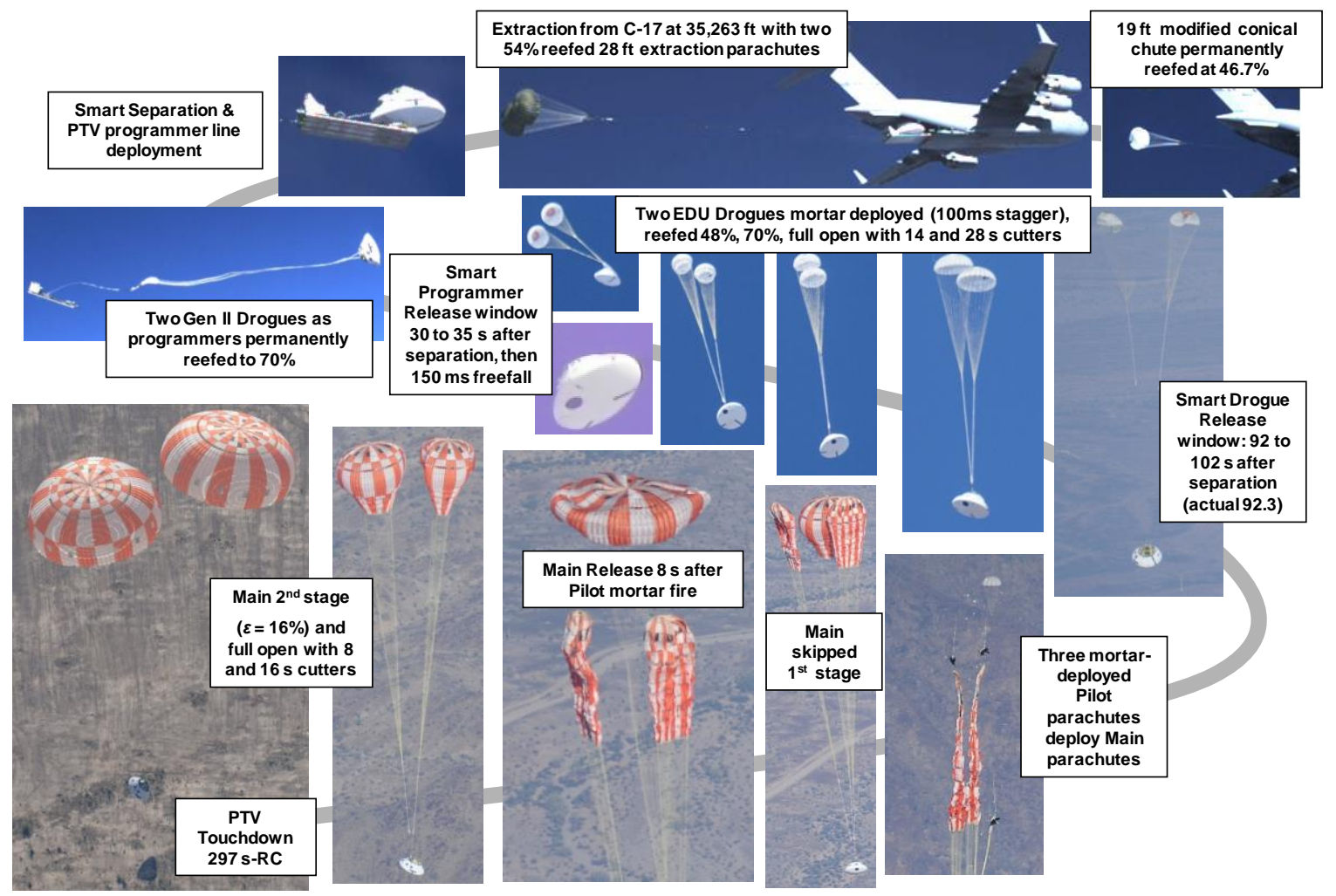

Figure 11. CDT-3-11 PTV concept of operations.

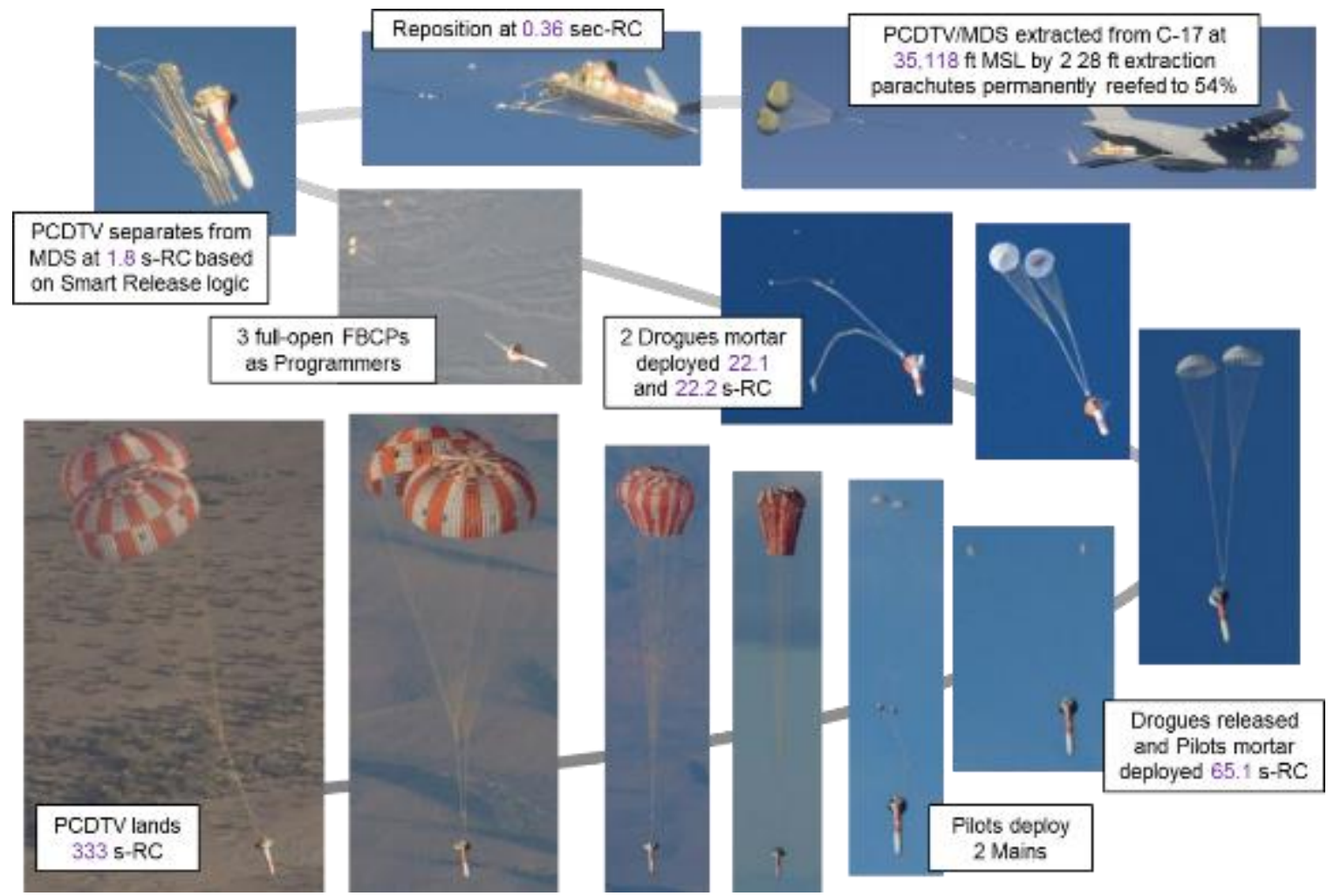

Figure 12. CDT-3-12 PCDTV concept of operations.

American Institute of Aeronautics and Astronautics 


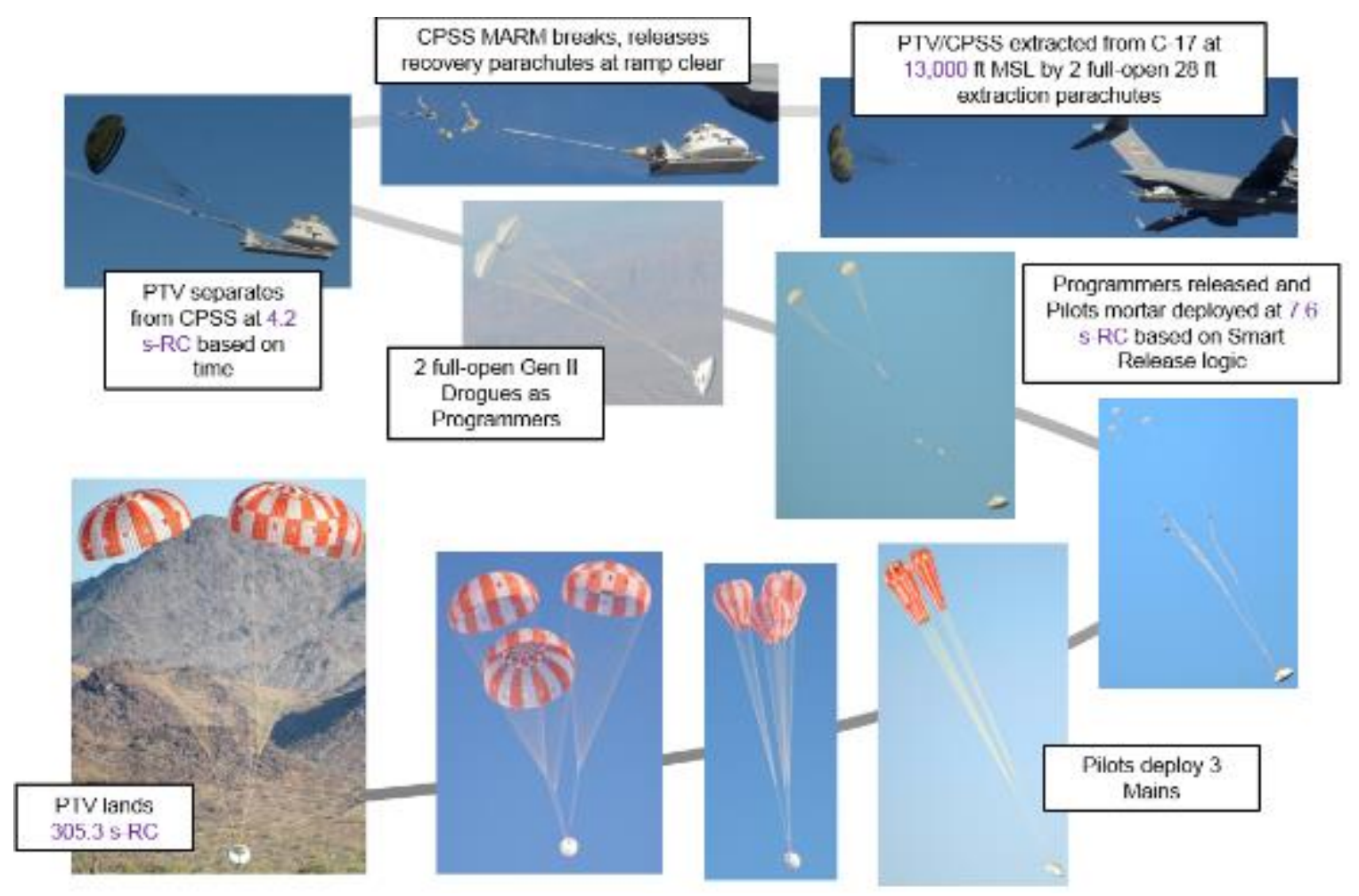

Figure 13. CDT-3-13 PTV concept of operations.

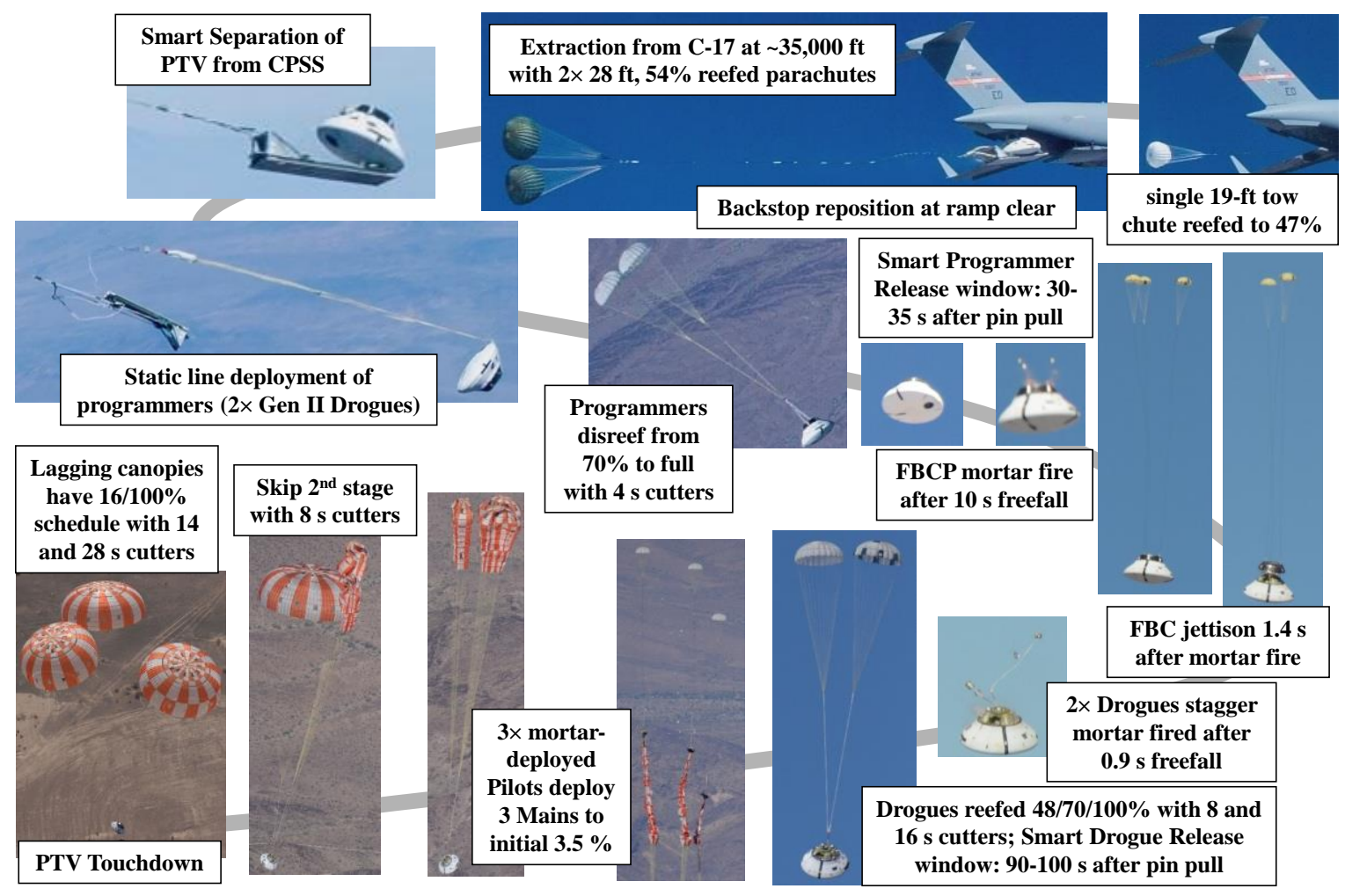

Figure 14. CDT-3-14 PTV concept of operations.

American Institute of Aeronautics and Astronautics 


\section{References}

${ }^{1}$ Olmstead, R., et al., "Overview of the Crew Exploration Vehicle Parachute Assembly System (CPAS) Generation I Drogue and Pilot Development Test Results," $20^{\text {th }}$ AIAA Aerodynamics Decelerator Systems Technology Conference, Seattle, Washington, May 2009, AIAA paper 2009-2939.

${ }^{2}$ Bledsoe, K.J., et al., "Overview of the Crew Exploration Vehicle Parachute Assembly System (CPAS) Generation I Main and Cluster Development Test Results," $20^{\text {th }}$ AIAA Aerodynamics Decelerator Systems Technology Conference, Seattle, Washington, May 2009, AIAA paper 2009-2939.

${ }^{3}$ Morris, A.L., et al., "Summary of CPAS Gen II Testing Analysis Results," $21^{\text {st }}$ AIAA Aerodynamic Decelerator Systems Technology Conference, Dublin, Ireland, May 2011, AIAA paper 2011-2585.

${ }^{4}$ Morris, A.L., and Olson, L.M., "Verification and Validation Plan of Flight Performance Requirements for Human Crewed Spacecraft Parachute Recovery Systems," $21^{\text {st }}$ AIAA Aerodynamic Decelerator Systems Technology Conference, Dublin, Ireland, May 2011, AIAA paper 2011-2560.

${ }^{5}$ Morris, A.L., et al., "Simulating New Drop Test Vehicles and Test Techniques for the Orion CEV Parachute Assembly System," $21^{\text {st }}$ AIAA Aerodynamic Decelerator Systems Technology Conference, Dublin, Ireland, May 2011, AIAA paper 2011-2616.

${ }^{6}$ Fraire, U., Anderson, K., and Cuthbert, P.A., "Extraction and Separation Modeling of Orion Test Vehicles with ADAMS Simulation," $22^{\text {nd }}$ AIAA Aerodynamics Decelerator Systems Technology Conference, Daytona, Florida, March 2013, AIAA paper 2013-1394.

${ }^{7}$ Romero, L.M. and Ray, E.S., "Application of Statistically Derived CPAS Parachute Parameters," $22^{\text {nd }}$ AIAA Aerodynamics Decelerator Systems Technology Conference, Daytona, Florida, March 2013, AIAA paper 2013-1266.

${ }^{8}$ Varela, J.G. and Ray, E.S., "Skipped Stage Modeling and Testing of the CPAS Main Parachutes," $22^{\text {nd }}$ AIAA Aerodynamics Decelerator Systems Technology Conference, Daytona, Florida, March 2013, AIAA paper 20131257.

${ }^{9}$ Ray, E.S., "Reefing Line Tension in CPAS Main Parachute Clusters," $22^{\text {nd }}$ AIAA Aerodynamics Decelerator Systems Technology Conference, Daytona, Florida, March 2013, AIAA paper 2013-1393.

${ }^{10}$ Bledsoe, K.J., "Application of a Smart Parachute Release Algorithm to the CPAS Test Architecture," $22^{\text {nd }}$ AIAA Aerodynamics Decelerator Systems Technology Conference, Daytona, Florida, March 2013, AIAA paper 20131392.

${ }^{11}$ Ray, E.S., "Reconstruction of Orion EDU Parachute Inflation Loads," $22^{\text {nd }}$ AIAA Aerodynamics Decelerator Systems Technology Conference, Daytona, Florida, March 2013, AIAA paper 2013-1260.

${ }^{12}$ Ray, E.S., Bretz, D.R, "Improved CPAS Photogrammetric Capabilities for Engineering Development Unit (EDU) Testing," $22^{\text {nd }}$ AIAA Aerodynamics Decelerator Systems Technology Conference, Daytona, Florida, March 2013, AIAA paper 2013-1258.

${ }^{13}$ Cassady, L.D., Ray, E.S., and Truong, T.H., "Aerodynamic Reconstruction Applied to Parachute Test Vehicle Flight Data Analysis," $22^{\text {nd }}$ AIAA Aerodynamics Decelerator Systems Technology Conference, Daytona, Florida, March 2013, AIAA paper 2013-1259.

${ }^{14}$ Moore, J.W. and Romero, L.M., "An Airborne Parachute Compartment Test Bed for the Orion Parachute Test Program," $22^{\text {nd }}$ AIAA Aerodynamics Decelerator Systems Technology Conference, Daytona, Florida, March 2013, AIAA paper 2013-1289. 
${ }^{15}$ Moore, J.W. and Fraire, U., "A Boilerplate Capsule Test Technique for the Orion Parachute Test Program," $22^{\text {nd }}$ AIAA Aerodynamics Decelerator Systems Technology Conference, Daytona, Florida, March 2013, AIAA paper 2013-1290.

${ }^{16}$ Ray, E.S., Hennings, E., and Bernatovich, M.A., “ Testing Small CPAS Parachutes Using HIVAS,” ,” $22^{\text {nd }}$ AIAA Aerodynamics Decelerator Systems Technology Conference, Daytona, Florida, March 2013, AIAA paper 20131309.

${ }^{17}$ Ray, E. S., “CPAS Parachute Compartment Drop Test Vehicle Analysis Report: EDU-A-CDT-3-1,” December 2011, ESCG-8400-11-CPAS-DOC-0175, Jacobs Sverdrup Engineering and Science Contract Group.

${ }^{18}$ Ray, E. S., “CPAS Parachute Compartment Drop Test Vehicle Analysis Report: EDU-A-CDT-3-2,” March 2012, ESCG-8400-12-CPAS-DOC-0017, Jacobs Sverdrup Engineering and Science Contract Group.

${ }^{19}$ Ray, E. S., “CPAS Parachute Test Vehicle Analysis Report: EDU-A-CDT-3-3,” June 2012, ESCG-8400-12-CPASDOC-0065, Jacobs Sverdrup Engineering and Science Contract Group.

${ }^{20}$ Ray, E. S., “CPAS Parachute Compartment Drop Test Vehicle Analysis Report: EDU-A-CDT-3-4,” July 2012, ESCG-8400-12-CPAS-DOC-0080, Jacobs Sverdrup Engineering and Science Contract Group.

${ }^{21}$ Ray, E. S., “CPAS Parachute Test Vehicle Analysis Report: EDU-A-CDT-3-5,” September 2012, ESCG-8400-12CPAS-DOC-0104, Jacobs Sverdrup Engineering and Science Contract Group.

${ }^{22}$ Ray, E. S., “CPAS Parachute Compartment Drop Test Vehicle Analysis Report: EDU-A-CDT-3-6,” December 2012, ESCG-8400-12-CPAS-DOC-0117, Jacobs Sverdrup Engineering and Science Contract Group.

${ }^{23}$ Bledsoe, K., “CPAS Parachute Test Vehicle Analysis Report: EDU-A-CDT-3-7,” August 2013, JETS-JE11-13SAIP-DOC-0026, JSC Engineering Technology and Science, Jacobs Engineering.

24 Ray, E., “CPAS Parachute Compartment Drop Test Vehicle Analysis Report: EDU-A-CDT-3-8,” August 2013, JETS-JE11-13-SAIP-DOC-0018, JSC Engineering Technology and Science, Jacobs Engineering.

${ }^{25}$ Ray, E., “CPAS Parachute Test Vehicle Analysis Report: EDU-A-CDT-3-9,” October 2013, JETS-JE11-13-SAIPDOC-0023, JSC Engineering Technology and Science, Jacobs Engineering.

${ }^{26}$ Ray, E., “CPAS Parachute Test Vehicle Analysis Report: EDU-A-CDT-3-11,” October 2013, JETS-JE11-13-SAIPDOC-0028, JSC Engineering Technology and Science, Jacobs Engineering.

${ }^{27}$ Ray, E., “CPAS Parachute Test Vehicle Analysis Report: EDU-A-CDT-3-12,” October 2014, JETS-JE11-14-SAIPDOC-0144, JSC Engineering Technology and Science, Jacobs Engineering.

${ }^{28}$ Moore, J.W., and Morris, A.L., "Development of a Smart Release Algorithm for Mid-Air Separation of Parachute Test Articles," 21st AIAA Aerodynamic Decelerator Systems Technology Conference, Dublin, Ireland, May 2011, AIAA paper 2011-2602.

${ }^{29}$ Hughes, M. and Ray, E.S., "Pendulum Overview (TBD Title)," 23 ${ }^{\text {rd }}$ AIAA Aerodynamics Decelerator Systems Technology Conference, Daytona, Florida, March 2015 (submitted for publication).

${ }^{30}$ Fraire, U., et al., "Extraction-Separation Performance and Dynamic Modeling of Orion Test Vehicles with Adams Simulation: 2nd Edition," 23 rd AIAA Aerodynamics Decelerator Systems Technology Conference, Daytona, Florida, March 2015 (submitted for publication).

${ }^{31}$ Ray, E.S., “A Symmetric Time-Varying Cluster Rate of Descent Model,” 23rd AIAA Aerodynamics Decelerator Systems Technology Conference, Daytona, Florida, March 2015 (submitted for publication).

American Institute of Aeronautics and Astronautics 
32 Day, J.D., "Reconstruction of Twist Torque in Main Parachute Risers," 23rd AIAA Aerodynamics Decelerator Systems Technology Conference, Daytona, Florida, March 2015 (submitted for publication).

${ }^{33}$ Wolf, D. and Fallon, E. J., "Reefing Line Loads for Ares Parachutes," $21^{\text {st }}$ AIAA Aerodynamics Decelerator Systems Technology Conference, Dublin, Ireland, May 2011, AIAA paper 2011-2619. 